\title{
Studies in Pyu Phonology, II: Rhymes
}

\author{
Marc Miyake \\ The British Museum \\ amritavira@gmail.com
}

\begin{abstract}
The extinct Pyu language was spoken during the first millennium CE and the early centuries of the second millennium CE in what is now Upper Burma. Pyu appears to be Sino-Tibetan on the basis of its basic vocabulary. It survives in inscriptions in an Indic script. This study reconstructs Pyu rhymes on the basis of spellings in those inscriptions and concludes that Pyu was an atonal language with 7 vowels and 18 final consonants. Some previous scholars have interpreted the subscript dots of the Pyu script as tone markers, but this study argues that they indicate fricative initials.
\end{abstract}

\section{Keywords}

Pyu - Sino-Tibetan - phonology - reconstruction - rhymes - tones

The extinct Pyu language was spoken during the first millennium CE and the early centuries of the second millennium CE in an urban Buddhist civilization located in what is now Upper Burma. On the basis of its basic vocabulary, Pyu appears to be Sino-Tibetan like the Burmese language that began to replace it in the late first millennium CE. Griffiths et al. $(2017 \mathrm{~b})$ provides the archaeological context for Pyu language studies.

Apart from a few transcriptions in the Chinese script, Pyu survives only in Indic-script inscriptions. Most long texts are on stone and are in poor condition. Few have dates and even fewer have dates

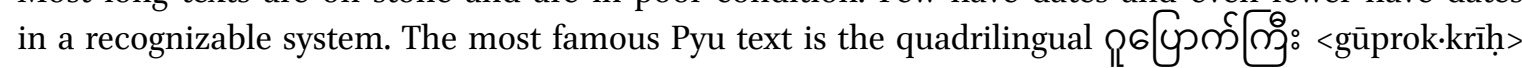
'Kubyaukgyi' inscription ${ }^{2}$ in Old Burmese, Old Mon, Pali, and Pyu. This 'Rosetta Stone' of Pyu

1 This study was conducted as part of the 'Beyond Boundaries: Religion, Region, Language and the State’ project (ERC Synergy Project 6og823 ASIA) under the supervision of Nathan W. Hill with cooperation from Arlo Griffiths and Julian K. Wheatley of the 'From Vijayapurī to Śrīkșetra? The Beginnings of Buddhist Exchange across the Bay of Bengal as Witnessed by Inscriptions from Andhra Pradesh and Myanmar' project funded by the Robert H.N. Ho Family Foundation.

2 This inscription is often anachronistically called $6600{ }^{\ominus}<$ mracetì $>$ Myazedi after a temple built centuries later. The inscription is conventionally referred to in the singular, even though it actually consists of two pillars with slightly different copies of the same text. 
decipherment was first analyzed by Blagden (1911), who was followed by many others since. Most studies of Pyu have focused on recovering the meaning of the Pyu faces of this inscription, but only a handful of other inscriptions have been studied, and much of the corpus remains unpublished except in electronic form at Griffiths et al. (2017a). Although there have been occasional attempts to reconstruct isolated aspects of Pyu phonology (e.g., Beckwith 2002's proposal of a vowel [ $\varepsilon]$; §8.1.6.1), there has never been any systematic reconstruction of vowels and codas. In this study, the first of its kind, I reconstruct Pyu rhymes by analyzing their spellings throughout the entire known corpus.

\section{Can Pyu spellings be taken at face value?}

Since Pyu was written in an Indic script, it is tempting to assume that all Pyu graphemes had Indic-like phonetic values. However, it is unlikely that a script optimized for one language would be a perfect fit for another. We might expect some degree of mismatch between the Indic script and Pyu phonology. And even if Pyu spelling is perfectly phonetic, we might expect some degree of innovation: new symbols and/ or new usages of existing symbols: e.g., in modern Mon, the anusvāra symbol $<\dot{\mathrm{m}}>$ for Indic nasals represents [?] in $\bigcap_{0}^{\circ}<$ gvam $>$ [k3̣? ] 'to obtain' and [h] and [o] in other words.

Moreover, sound changes can cause even the most precise phonetic script to lose its initial transpar-

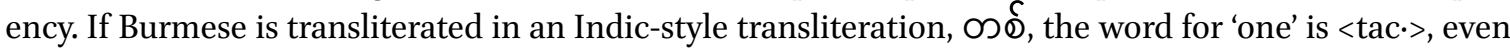
though it is actually pronounced [tI?]. This is because the rhyme *ac has regularly become [I?] in Burmese (Yanson 2015:108). ${ }^{3}$

Given the above facts about Mon and Burmese, it would be hazardous to interpret the Pyu word for

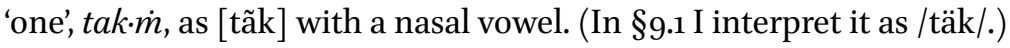

Aware of the dangers of a naïve reading of the Pyu script, I can only recover what Yabu Shirō (1996) called sonus grammae, the sound system implied by a writing system. This implied system may only reflect part of a lost whole.

\section{$3 \quad$ Methodology}

\subsection{Corpus}

This study relies on Griffiths et al. (2017a), an online corpus of Pyu inscriptions.

Most inscriptions are undated. Only a few have terminus a quo dates in the $11^{\text {th }}$ or $12^{\text {th }}$ centuries or dates in an unknown calendar. The $11^{\text {th }}$ and $12^{\text {th }}$ century texts are in what Shafer $(1943: 316)$ called 'Late Pyu'; they have phonological, syntactic, and/or lexical characteristics that differentiate them from the rest of the corpus which Shafer (1943:316) regarded as 'Old Pyu'. The earliest of the Old Pyu texts may be inscription 16, a bilingual text whose Sanskrit portions are in early $6^{\text {th }}$ century Northern Brāhmī script (Griffiths et al. 2017b:100).

Some Pyu inscriptions have subscript final consonants, whereas others do not. Inscription 8, one of the copies of the Kubyaukgyi inscription, only has subscript final consonants in its first three lines. I have not found any correlation between the presence or absence of subscript final consonants and geography or chronology.

3 Yanson actually writes [i?], but I have rewritten the rhyme as [I?] because the modern Burmese vowel is slightly lower than $[\mathrm{i}]$. 


\subsection{Conventions}

All quoted Pyu forms are followed by their source's inventory number from Griffiths et al. (2017b). Arabic numerals following inventory numbers refer to lines. Roman numerals following inventory numbers refer to sections of texts. Letters after inventory numbers refer to faces on an inscription. Letters for oddnumbered faces are capitalized: e.g., capital A for the first face but lowercase $b$ for the second. Citations are not comprehensive; only one example is given per form unless I am discussing frequency. Old Mon and Old Burmese forms in Pyu multilingual texts are also cited by inventory numbers using the same conventions.

Pyu, Old Mon, and Old Burmese transliterations are in an Iso (International Organization for Standardization) 15919-style romanization for Sanskrit with three modifications. First, a raised circle ${ }^{\circ}$ distinguishes independent vowel characters from dependent vowel characters: e.g., ${ }^{\circ} \mathrm{o}$ is an independent vowel character whereas $o$ is a dependent vowel character that must be attached to a consonant character. Second, $m$ represents a subscript dot rather than Gurmurkhi țippī (or an anusvāra in non-ISO 15919 romanizations). Third, middle dots follow subscript consonants for codas and precede transliterations of the subscript dot (ṃ), anusvāra $(\dot{m})$, and visarga (ḥ): e.g., del.ṃm coda $l$.

I italicize Pyu transliterations but distinguish between italics for conventional non-IPA transcriptions and angle brackets for transliterations of all languages other than Pyu: e.g., Thai ทัณฑฆาต thanthákhâat $<$ dănaḍaghāta $>$ (cf. IPA [ $\left.\left.\left.\mathrm{t}^{\mathrm{h}} \mathrm{an} \dashv \mathrm{t}^{\mathrm{h}} \mathrm{a}\right\rceil \mathrm{k}^{\mathrm{h}} \mathrm{a} \mathrm{t} \mathrm{V}\right]\right)$.

\subsection{Scope}

The Pyu lexicon has two major components: Indic and non-Indic. This study focuses on the rhymes of 1,702 unique Pyu non-Indic 4 akșaras (written syllabic units) extracted from Griffiths et al. (2017a) and collated in a CSV file (Miyake 2018). Parentheses indicate editorial restorations. Brackets indicate uncertain readings. Capital C and V indicate unknown consonants and vowels. Dagger symbols $(\dagger)$ indicate expected but unattested forms. I have excluded partly illegible and uncertain akșaras from my analysis unless their definitely legible portions contain truly unique patterns.

\subsection{Asemantic phonology}

Proper phonology relies on minimal pairs - nearly homophonous words with different meanings - for the identification of phonemes. Unfortunately, the vast majority of words in Pyu texts have no known meanings. Even word boundaries are often unclear due to the absence of word spacing in the Pyu script.

The only uncontroversial units in the script are akșaras which may or may not correspond to morphemes. When I am unable to identify words or morphemes, I will use the term 'akșaras' to avoid judging the semantic status of monosyllables and sesquisyllables. The term 'akșaras' is also less unwieldly than 'monosyllables and sesquisyllables'.

I will attempt what I call 'asemantic phonology': the identification of phonemes on distributional grounds without reference to semantics. I will provisionally regard any two graphemes in the same position in an akșara as distinct phonemes unless there are distributional and/or typological reasons for

4 I use the term 'non-Indic' because in most cases I am not sure whether a given Pyu morpheme is native or borrowed from a non-Indic source. 
doubt. For concrete examples of this methodology, see $\$ 8.2$ in which I reject a literal interpretation of the script that would require postulating dubious vowel phonemes.

\section{$4 \quad$ From aksaras to syllables}

Before delving into the arrangement of phonemes in Pyu syllables, I will describe the arrangement of graphemes into akșaras in the Pyu script. I will explain how these graphemes correspond to phonemes in $\S 5^{-10}$.

\subsection{Akșara structures}

4.1.1 Structure of akșaras without independent vowel symbols

Nearly all Pyu akșaras have a $\mathrm{C} a$ consonant symbol at their core. That symbol has an inherent $a$ vowel unless another vowel symbol $V$ is added. Other symbols surround this $C a$ symbol. A maximal akșara has up to eight optional components that I indicate in parentheses.

$$
(r) C_{1} a\left(C_{2}\right)\left(C_{3}\right)(V)(C \cdot)(m)(\dot{m})(h)
$$

Two exceptions to that formula are a single instance of double vowel marking (pri; $32.5 ;$ §8.2.2) and a single instance of double subscript consonants (rlar.r.; 55; §9.3).

4.1.2 Structure of akșaras with independent vowel symbols

Other exceptions to the formula in $§ 4.1 .1$ have independent vowel symbols $\left({ }^{\circ} V={ }^{\circ} a,{ }^{\circ} i,{ }^{\circ} o\right.$, and possibly $\left.{ }^{5}{ }^{5} ; \S 8.1 .3\right)$ instead of $C_{1} a$ :

$$
(\dot{m})^{\circ} V(h)(C \cdot)
$$

Akșaras with independent vowel symbol cores have far fewer optional components.

\subsection{Inventories of graphemes for rhymes}

Only positions with more than one possible grapheme are listed below. Graphemes are displayed in an arrangement based on the Sanskrit phonemic inventory table in Bucknell (1994:73).

See Table 4 in $\S 7$ for graphemes corresponding to onset phonemes.

\subsubsection{Vowel graphemes}

There are 9 vowel symbols (Table 1). All symbols for Sanskrit and Pali vowels are represented except for long $\bar{r}, l$, and the theoretical long $\bar{l}^{6}$

5 Previously published tables of the Pyu script (e.g., Tha Myat 1963:1) contain more independent vowel symbols. However, symbols such as ${ }^{\circ} e$ that are not listed here are absent from Pyu-language texts in the Pyu script, though they may be present in Sanskrit and Pali texts written by the Pyu in special scripts for Indic languages distinct from the script they used for their own language. The conflation of these scripts as a single 'Pyu script' is common in the literature.

6 Although there are no actual Sanskrit words with long $\bar{l}$, the independent vowel symbol $\mathfrak{\emptyset}<<$ إ̊ represents the Khmer word [li: 'to hear', and ภา <إ > is an obsolete spelling of Thai ลือ [lus:-1] 'to rumor', so $\bar{l}$ would not be entirely unexpected for [l] followed by a high vowel in a Southeast Asian context. Short $r$ sometimes represents Pyu /ri/ (\$8.2.2). 


\begin{tabular}{llcr} 
TABLE 1 & \multicolumn{3}{c}{ Pyu vowel graphemes } \\
\hline$a$ & $\bar{a}$ & & \\
$i$ & $\bar{\imath}$ & $e$ & $a i$ \\
$r$ & & & \\
$u$ & $\bar{u}$ & $o$ & $a u$ \\
& & & \\
\hline
\end{tabular}

Table 1 excludes the aforementioned single case of double vowel marking: pri $(32.5 ; § 8.2 .2)$.

4.2.2 Subscript final consonant graphemes

There are only 10 possible subscript final consonant symbols (Table 2). Middle dots distinguish them in transliteration from consonant symbols in other positions.

\section{TABLE 2 Pyu subscript final consonant graphemes}

k. $\quad \dot{n}$

\begin{tabular}{|c|c|}
\hline & $n$. \\
\hline & $m$ \\
\hline
\end{tabular}

Table 2 excludes the aforementioned single case of double subscript consonants: $r$ lar.r. $(55 ; § 9 \cdot 3)$.

Although akșaras typically represent syllables in Indic scripts, improbable initial consonant clusters such as $t d$ in the Pyu script suggest that at least some $a k s$ aras may represent sesquisyllables. The $t$ - of the written cluster $t d$ - almost certainly reflects a presyllable, but at this stage of research, it is not possible to determine whether most written clusters corresponded to presyllable-initial sequences or true initial clusters: e.g., I do not know whether tyain. /t.jay/ '?' (20.1) was phonetically [təjay], [tjay], or both in synchronic variation.

For now I will use the agnostic term 'preinitial' to refer to the first consonant in a written Pyu consonant cluster. The consonant following this 'preinitial' is the 'initial'.

Pyu has the following phonemic (sesqui)syllable structure:

$$
/(\mathrm{C}) \cdot(\mathrm{C}) \mathrm{V}(\mathrm{C}) /
$$

I use a period to separate all preinitials from initials, regardless of whether there might have been a short unstressed vowel between them. Future studies may clarify which written clusters were broken up by unwritten vowels.

I make a distinction between core and peripheral consonants. I am absolutely certain about the phonemic status of core consonants. I am far less certain about peripheral consonants which are low in 
frequency and may reflect subphonemic or even nonphonemic phenomena (e.g., pseudo-Indic spellings or errors).

\section{$6 \quad$ Preinitials}

Table 3 lists the most common preinitials.

TABLE 3 Pyu core preinitials

/k./

$|\mathrm{r}$.

$\begin{array}{lll}\text { /s./ } & \mid \mathrm{t} . / & \mid \mathrm{n} . / \\ & / \mathrm{p} . / & \mid \mathrm{m} . /\end{array}$

I exclude peripheral preinitials such as $\dot{n}(20.4)$ from this study of rhymes. Such rare preinitials may reflect allophones or be scribal errors.

\section{$7 \quad$ Initials}

Table 4 lists the most common initials. I provide transliterations whenever they differ from my phonemic notation.

TABLE 4 Pyu core initials

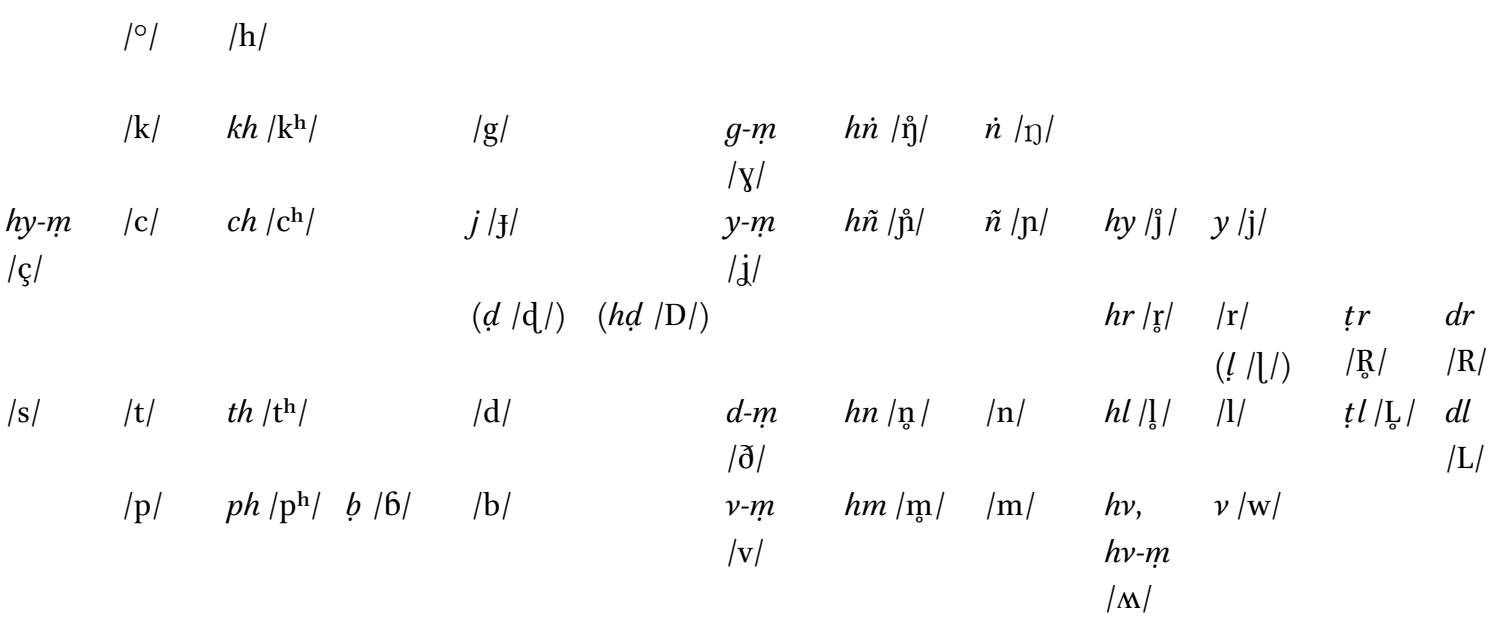

My phonemic interpretation of initial symbols is straightforward with the following exceptions.

I phonemicize the initial of akșaras written with vowel-initial symbols as $/ \%$, a placeholder symbol which may represent either a glottal stop or zero.

Phonemes in parentheses are unique to Late Pyu. 
Capital letters indicate phonemes whose phonetic qualities are uncertain.

$h d, t r, d r, t l$, and $d l$ are unit phonemes. None can be interpreted as preinitial-initial sequences. $h$ and $t$ are not attested as preinitials before other consonants. $d$ is almost never followed by consonants other than $r$ and $l$.

Pyu shares the symbol $b$ with Old Mon. I carry over its Old Mon phonemic value / $6 /$ into Pyu. There is no evidence for an alveolar implosive $+/ d /$ like that of Old Mon.

I justify my interpretation of written consonant- $m$ sequences in $§ 10.8$.

I exclude peripheral initials such as $g h(17.1,20.2,100)$ from this study of rhymes. Such rare initials may reflect allophones or be pseudo-Indic spellings of core initials.

\section{$8 \quad$ Vowels}

The situation with vowels is clearer than that for consonants, so I will dispense with the core/peripheral distinction; vowels are either accepted or rejected.

\subsection{Accepted vowels}

I reconstruct a symmetrical seven-vowel system (Table 5).

\begin{tabular}{lll} 
TABLE 5 & Pyu vowel phonemes and their spellings \\
\hline$i, \bar{\imath} / \mathrm{i} /$ & $i \dot{m}, \bar{\imath} \dot{m} / \ddot{\mathrm{i}} /$ & $u, \bar{u} / \mathrm{u} /$ \\
$e,(\operatorname{a\dot {m}}) / \mathrm{e} /$ & $o, a u / \mathrm{o} /$ \\
$a \dot{m} / \ddot{\mathrm{a}} /$ & $a, \bar{a} / \mathrm{a} /$
\end{tabular}

Six vowel phonemes have more than one spelling. I explain my reasoning for not taking those multiple spellings at face value in the following sections.

I use non-IPA symbols for two vowel phonemes (/ä/ and /ï/) because I am unable to propose specific phonetic values for them. I describe their recoverable phonetic features in §8.1.6.1 and §8.1.6.2.

Table 5 excludes anomalous spellings that I discuss in $§ 8.2$.

\subsection{1 /a/}

This phoneme is almost always spelled with the inherent vowel of Ca akșaras. The only exceptions are $j \bar{a}$ '?' (100), vān்.m '?' (27.2), and yāḥ '?' (20.1), which may be variant spellings or homophones of ja '?' (7.24), van்.m 'plural marker' (16.3C), and yah '?' (16.5C). If Pyu had a phoneme /a:/, ā would be much more common. Moreover, 'aryya- with a short $a$ for Sanskrit ärya- 'noble' with long $\bar{a}\left(16.2 \mathrm{~A}\right.$ and $\left.{ }_{16.5} \mathrm{~A}\right)$ in a SanskritPyu bilingual inscription is an error expected from a speaker of a language without a distinction between /a/ and /a:/.

I reconstruct /a/ as low unlike the schwa of Sanskrit and Pali short $a$. Those languages have a short mid $a$ and a long low $\bar{a}$. Since I reject a short /a/ : long /a: / contrast for Pyu, Pyu only had a single /a/ phoneme. If I interpreted that phoneme as mid /ə/, Pyu would have a strange vowel system without a low /a/.

7 I exclude the spelling ai because it represents a vowel-coda sequence /aj/ rather than a single vowel phoneme ( $\$ 8.2 .3)$. 
Early Sino-Tibetan words for 'five' support a low interpretation of Pyu /a/. Old Chinese 五 * $\mathrm{y}^{\varsigma} \mathrm{a}$, Old Tibetan lnga, and Old Burmese ngā all contain an $a$ vowel corresponding to the /a/ of Pyu pimina /pï ya/ 'five' (3) and $\dot{n} a$ in $\dot{n} a$ su / ga su/ 'fifty' (lit. 'five ten'; 5).

/a/ may have been low back [a] for maximal contrast with the front low or lower mid vowel /ä/ (§8.1.6.1). Although I place /a/ in the low back corner of Table 5 for symmetry, /a/ could also have been central. In either case, it is backer than /ä/.

\subsection{2 /i/}

This phoneme is spelled $i$ in non-Indic loans with only four exceptions: tīm (26.3), nïl (27.2), vīmm (27.4, 27.5, 27.7), and $h d \bar{\imath}$ (8.20; probably also in the corresponding passage in 7.20, though the $\bar{\iota}$ there is unclear).

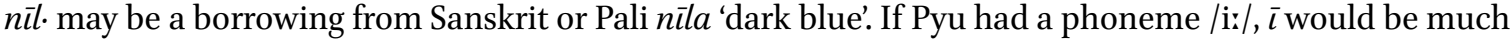
more common. The spellings of Sanskrit siddha( $m)$ 'success' as sit.dha (20.5) and siddham. (27.1) with an unnecessary long $\bar{\imath}$ is a hypercorrection expected from a speaker of a language without a distinction between /i/ and /i $/$. There is not a single Indic loanword in Pyu with an $\bar{\iota}$ corresponding to an Indic $\bar{\imath}$.

$i$ may have had a lowered allophone like [I] before /y/ in iy. /ij/ to maximize a distinction between /ij/ and $/ \mathrm{i} /$. This lowering is parallel to the possible lowering of $/ \mathrm{u} / \mathrm{in} / \mathrm{uw} /(\S 8.1 .3)$.

8.1.3 /u/

This phoneme is usually spelled $u$, though a less frequent variant spelling $\bar{u}$ occurs mostly after labials (Table 6).

\begin{tabular}{|c|c|c|c|}
\hline Akșara & Text & Similar akșara with $u$ & Text \\
\hline kūn. & 20.4 & kun. & 29 \\
\hline$t u \bar{n} \cdot h \underline{h}$ & 20.3 & None & None \\
\hline$[t] \bar{u} m \cdot$ & 32.6 & tum. & $16.2 \mathrm{~b}, 16.3 \mathrm{~A}, 20.1$ \\
\hline$n \bar{u}$ & 20.5 & $n u$ & 17.1, 20.3, etc. \\
\hline$p \bar{u}$ & $20.1,21.1,39.3$ & $p u$ & 19.1, 21.3, etc. \\
\hline pūḥ & 21.5 & None & None \\
\hline pūn். & 32.3 & None & None \\
\hline pūp. & 20.5 & None & None \\
\hline$p \bar{u} r \cdot \dot{m} h \underline{n}$ & 32.5 & None & None \\
\hline$m \bar{u}$ & $20.4,21.1,21.6$ & $m u$ & $19.2,20.5$, etc. \\
\hline$m \bar{u} h$ & $21.5,25 \cdot 3$ & muh & 21.4 \\
\hline$m \bar{u} \dot{n} \cdot h$ & $20.3(2 \times), 27 \cdot 3,32.7,3^{2.8}$ & None & None \\
\hline$m \bar{u} m \cdot$ & $23 \cdot 4$ & None & None \\
\hline$r \bar{u}$ & $99,135,136$ & ru & 3,4 , etc. \\
\hline
\end{tabular}

Table 6 excludes the uncertain akșara ${ }^{\circ} \bar{u}(170)$ which might be read $\tilde{n} a$.

A third of $\bar{u}$-spellings (8/25) occur in only one text (20), one-fifth $(5 / 25)$ occur in 32 , another fifth $(5 / 25)$ in 21 , and the remainder are scattered across seven texts $(23,25,27,39,99,135,136)$. Although the scribes of 20, 21, and 32 favored $\bar{u}$ more than most of their peers, $\bar{u}$ is not a geographically isolated spelling, as it occurs not only in texts from the Sriksetra area but also in the Tondaw inscription in Rakhine (23), the 


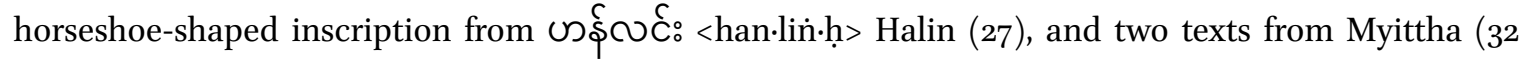
and 39 ).

$\bar{u}$ may have represented an allophone of $/ \mathrm{u} /$ after labials. I doubt that allophone was long [u:] since I do not reconstruct any other long vowels in Pyu. Also, the spelling buudha (20.1) for Sanskrit/Pali buddha may indicate that the Pyu lacked a distinction between /u/ and /ui/. Perhaps $\bar{u}$ was a diphthong like [əu] that had partially dissimilated from the preceding labial. To Pyu ears, [əu] might have sounded as long as an Indic $\bar{u}$.

The handful of instances of $\bar{u}$ after nonlabial consonants may be (a) evidence of the spread of the allophone $[\partial u$ ] to other environments, (b) pseudo-Indic spellings of non-Indic words with a long vowel symbol usually reserved for Indic loanwords, or (c) errors. Bricks such as 135 and 136 often contain unusual and sometimes even unidentifiable symbols.

Another possibility is that what Griffiths et al. (2017a) read as $p \bar{u}$ may in fact be a similar-looking ${ }^{\circ} a$ which is only attested once in a non-Indic akșara $\left({ }^{\circ}\right.$ at $\left.\cdot \dot{m} h, 25 \cdot 7\right)$.

$u$ may have had a lowered allophone like [ $\mathrm{\sigma}$ before $/ \mathrm{w} / \mathrm{in} u v \cdot \mathrm{uw} /$ to maximize a distinction between $/ \mathrm{uw} /$ and $/ \mathrm{u} /$. This lowering is parallel to the possible lowering of $/ \mathrm{i} / \mathrm{in} / \mathrm{ij} /(\S 8.1 .2)$.

\subsection{4 /e/}

/e/ is the rarest of the vowels. It has only a single spelling $e$ except in texts in which /e/ and $a \dot{m} / \ddot{a} /$ were merged into /e/ (\$8.1.6.1).

8.1.5 /o/

/o/ has two spellings: $o$ and a less common $a u$. They are in nearly complimentary distribution.

$a u$ is attached to $p, m, s$, and $h$ with a single exception: gaum 'cave' (16.2A), a loanword from Sanskrit/ Pali guhā, is probably an error for gom (7.19; cf. Old Mon goḥh. 'id.' 7.4).

$o$ is attached to all other consonants with only three exceptions:

pto '?' (17.5) instead of †ptau

so '?' (39.7) instead of †sau; this akșara is difficult to read and may be something else.

hoh 'three' $(7.6,7.12,7.21,8.6,8.21)$ instead of nhoh as in other lines of those texts $(7.5,8.5,8.13)$ and in other texts $(20.1,73)$ or hauh as in 3 ; the $n$ in the $n h$-ligature is tiny, so $n h$ could easily be confused with $h$.

If $a u$ represents a phoneme /au/, its distribution is very unusual. There is no phonetic reason for /au/ to only follow $/ \mathrm{p}(. \mathrm{C}) \mathrm{m}(. \mathrm{C}) \mathrm{s}(. \mathrm{C}) \mathrm{h}(. \mathrm{C}) /$ which do not constitute a natural class. They do, however, constitute a graphic class: all of those consonant symbols contain U-like shapes, and the normal T-like $o$ symbols might look awkward floating in space atop the hollow part of the U-shape. Most scribes resolved this problem by replacing $o$ with two strokes for $a u$ on the top left corner of the U-shape, though a few attached $o$ to the top left corner of the U-shape (e.g., pto '?' 17.5).

\subsubsection{Vowels written with anusvāra}

The anusvāra is very common in Pyu texts, but it is found almost exclusively above $\mathrm{Ca}$ and $\mathrm{Ci}$ non-Indic akșaras with seven exceptions (see $\$ 8.2 .1$ for details): Four of those exceptions have counterparts without anusvāra (§8.2.1.1, §8.2.1.3, §8.2.1.4). However, there is no guarantee that other pairs of akșaras distinguished solely by the presence or absence of an anusvāra represent the same syllable or even the same morpheme or part of a morpheme.

The restricted distribution of the anusvāra makes Blagden (1911:373) and Luce's (1985:63) interpretation of the anusvāra as a tone mark highly improbable since languages in the area do not restrict any tones to a small subset of the vowel system. 
That restricted distribution also casts doubt on the anusvāra representing a nasal or nasalization as in Indic usage or as in Katō's (2005) reconstruction unless Pyu had only two nasal vowels /ã ĩ/. It would not be surprising if Pyu had fewer nasal vowels than oral vowels: cf. Polish which has six oral vowels /a i u i e o/ but only two nasal vowels /ẽ õ/ (Rothstein 1993:688). But comparative evidence indicates that the anusvāra was not nasal for four reasons:

First, there are no known sets of spellings for the same morpheme or part of a morpheme with anusvāra-nasal alternations. If $\dot{m}$ were another spelling of $/ \mathrm{m} /$, an $/ \mathrm{m} /$-final morpheme such as lam. 'path' (16.1C) might have $\dot{m}, m \cdot$, and perhaps even $m \cdot \dot{m}$ spellings like Old Mon /klom/ 'hundred' which was spelled $\langle$ klam $\cdot\rangle,\langle$ klam $>$, and $<$ klam.m $\rangle$ (Shorto 1971:63). ${ }^{8}$ This is the weakest argument because in theory such sets may await discovery.

Second, the anusvāra appears in Indic loanwords where no anusvāra is expected: e.g., mugaṃtubudim $<$ Pali Muggaliputtati (name of a senior monk; 8.15).

Third, the anusvāra is missing from Indic loanwords where it might be expected: e.g., -badimmm $<$ Sanskrit or Pali -pandita 'pundit' (7.17) in which the anusvāra is in the second syllable but not the first where it could have corresponded to $n$. No Indic loanwords contain am despite the high frequency of $a$-nasal sequences in Sanskrit and Pali.

Fourth, the anusvāra does not correspond to a nasal in Sino-Tibetan cognates: e.g.,

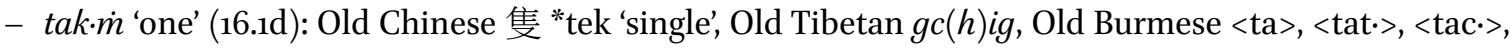
$<$ tic. $>,<$ tec $\cdot>,<$ tij. $>9{ }^{9}{ }^{*}$-ik 'one'

- plam 'four' (4): Old Chinese 四 *s-li-s, Old Tibetan bźi, Old Burmese <lī >, <liy•> 'id.'

- hnim 'seven' (5), possibly also hnit.m in a text with final subscript consonants (20.4): Old Chinese 七

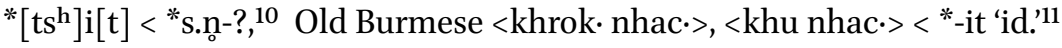

- hram 'eight' (6); possibly also hrat.m in texts with final subscript consonants (20.1 and 159): Old Chi-

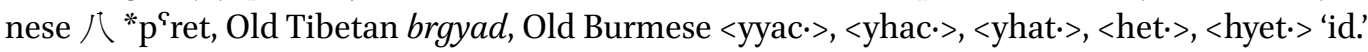

- paimh 'to give' (7.5): Old Chinese 界 *pi[t]-s, Old Burmese <piy·> (7.9) 'id.'

If the anusvāra did not represent a nasal, what did it represent?

\subsubsection{1 / / / $/$}

Beckwith (2002:159) proposed that aim was $[\varepsilon]$ but did not fully explain his reasoning beyond mentioning the minimal pair of plam 'four' and pli 'grandson'12 and Old Tibetan brgyad 'eight', a cognate of Pyu hram

8 I have converted Shorto's Old Mon transliterations into the system used for all Indic scripts in this article.

9 The Old Chinese forms in this section are cited from Baxter and Sagart (2014b). The Old Burmese numerals are cited from Luce (n.d. A).

Brackets indicate uncertainty. Although it is certain that 'seven' had initial $t$ sh-in Middle Chinese, that onset has multiple Old Chinese sources, and there is no Chinese-internal evidence pointing to any particular source. However, I think the Chinese-external evidence - namely, Sino-Tibetan cognates - points to *s.n- which Baxter and Sagart (2014a:151) reconstruct as one possibile source of Middle Chinese $t$ sh-.

11 Although Old Burmese 'seven' and perhaps Old Chinese 'seven' contained a nasal onset, the other cognates do not contain nasals, so one cannot posit a correspondence between non-Pyu nasal onsets and Pyu anusvāra.

12 Beckwith does not specify where he found this minimal pair. I presume he found it in inscription 1, the only text containing both words. The $[p]$ of $[p] l i$ 'grandson' is not clear in inscription 1 . There is no inscription in which both plam 'four' and pli 'grandson' are clearly written. 
'id.. He concluded from 'four' and 'grandson' that am "was perhaps closer to $[\varepsilon]$ than to [i] as in Burmese", presumably because 'four' was written with the low inherent vowel $a$ rather than with mid $e$ or high $i$. I infer from his Old Tibetan reference that he thought $[\varepsilon]$ might be a monophthong combining the palatality of Old Tibetan $-y$ - $[\mathrm{j}]$ with the lowness of Old Tibetan and Pyu $a$.

Even if it is true that Pyu am corresponds to Old Tibetan $y a$ and to front vowels in Old Chinese and Old Burmese, that does not guarantee it is low and front; it could have raised and/or backed at a later period. The Late Middle Chinese final that Pulleyblank (1991) reconstructed as *-ja: corresponds to [o] in some $\mathrm{Wu}$ varieties of Chinese: e.g., the Shanghai reflex of Pulleyblank's (1991:334) Late Middle Chinese 夏

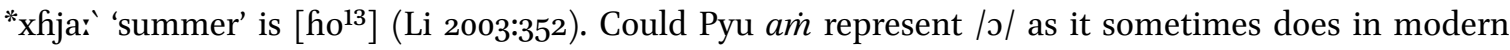
Mon? ${ }^{13}$ A superscript dot need not imply frontness, just as it need not imply nasality; it merely tells us that aim was somehow different from Indic $a$ but not exactly how.

A lower mid interpretation of $a \dot{m}$ accounts for its absence in Indic loanwords. There was no need to write an $[\varepsilon]$ or $[0]$ that did not exist in either Sanskrit or Pali.

Most importantly, internal Pyu evidence supports a front interpretation of am: paimh 'to give' also appears once as [peh] (16.4C). If Griffiths et al.'s (2017b:96) reading of that unclear akșara is correct, the scribe may have spoken a dialect in which $a \dot{m}$ and $e$ had merged into /e/.

To avoid implying a precise phonetic value of $a \dot{m}$ which could have been $[æ],[\varepsilon]$, or in the case of the scribe above, [e], I will write that phoneme with a non-IPA symbol/ä/. Beckwith's symbol $\dot{a}$ with a single dot is difficult to type and is far less familiar than $\ddot{a}$ whose pronunciations in European languages give an idea of the possible phonetic range of aim: e.g., [e:] for "the average speaker" of German (Eisenberg 1994:351), $[\varepsilon(:)]$ and $[æ(:)]^{14}$ in Swedish (Holmes and Hinchliffe 1997:7), and [æ] in a conservative pronunciation of Slovak (Stone 1993:534). Moreover, the only language I know of with a single-dotted $\dot{a}$ in its orthography is Ulithian in Micronesia with only a thousand speakers (Simons and Fennig 2018). ${ }^{15} \stackrel{a}{a}$ with a ring reminiscent of the anusvāra is more familiar than $\dot{a}$, but $\stackrel{a}{a}$ might be misinterpreted as a back rounded vowel like its Swedish values [o] and [o:].

\subsubsection{2 /ii}

If am represents a vowel phoneme, then it is likely that the other high-frequency vowel-anusvāra combination, $i \dot{m}$, also represents a vowel phoneme. Determining the identity of the latter phoneme is much more difficult. Obviously it must have resembled $i$ in some way: not only was it written with $i$, but it also corresponds to $i$ in Indic loans (e.g., -adimmintya < Sanskrit -âditya 'sun' (7.3)) and even to Old Chinese *i and pre-Old Burmese *i in 'seven' (§8.1.6).

I write that phoneme with a non-IPA symbol/ï/ by analogy with/ä/ for the phoneme written as am. I use the non-IPA symbol /i// to mimic the Pyu spelling combining $i$ with a superscript dot and to avoid committing to a specific phonetic value. The letter $\ddot{i}$ could imply a high vowel that is neither palatal nor labial: e.g., central [i] or back [u]. Both of those vowels are possible phonetic values for /ï/; another is schwa which is the sort of colorless vowel that might be expected in presyllables such as pim- in pimina 'five' $(4)^{16}$ and in high-frequency function words such as the realis marker bin.mị $\sim$ bim $\grave{h} \sim$ bim $h$ and the

I do not intend to suggest that the Pyu would have written / / / as am because of Mon influence or vice versa; simple diacritics such as dots can be independently used for similar purposes.

14 In Swedish, $\ddot{a}$ is $[æ(:)]$ before $/ \mathrm{r} /$ and $[\varepsilon(:)]$ elsewhere (Holmes and Hinchliffe 1997:6).

15 Ulithian single-dotted $\dot{a}$ represents the low front vowel/æ/( Sohn and Bender 1973:17-18) which is a possible value of Pyu/ä/.

16 pimna is the only known potential case of a sesquisyllable /p.ya/ written as a disyllable. It also may reflect a conservative disyllabic pronunciation /pï ya/. Old Mon has disyllabic spellings of sesquisyllabic words: e.g., kucit. as well as kcit. for / kəcøt/ 'to kill' (Shorto 1971:45). 
locative marker tim. im may represent an unstressed reduced vowel in Indic loans: e.g., viṃmkhno /wïk. no/ 'Vishnu' (17.2) could have been pronounced [wə ' $\mathrm{k}^{\mathrm{h}}$ no] or [wə $\mathrm{k}^{\mathrm{h}}$ ə 'no] with rGyalrong-style double presyllables and final stress. One more possibility for /i/ is [I]. Those possibilities need not be exclusive, as the phonetic manifestation of /i/ could have varied in different phonetic environments and over space and time: cf. how Common Slavic *i has become [I] in Ukrainian and [i] elsewhere (De Bray 1980:114, 196). ${ }^{17}$

The Pyu corpus is spread over a wide area and spans centuries, so its relatively uniform orthography may disguise an unknown degree of phonetic diversity that is only hinted at by a few deviant spellings. One would not be able to reconstruct the diversity of modern English pronunciation from a far larger corpus.

\subsection{Rejected vowels}

These rare vowel symbols probably do not represent vowel phonemes other than those already listed in Table 5 .

8.2.1 Vowels with anusvära other than $a$ or $i$

There are only seven distinct akșaras containing such vowels. I comment on specific vowel-anusvära combinations below.

\subsubsection{1 $\quad \bar{i} \dot{m}$}

ìm occurs solely in viṃm '?' in an inscription from Halin (27.4, 27.5, and 27.7). That inscription also contains vimmm '?' (27.2) without a long vowel, an akșara found in several other texts from different sites (e.g.,

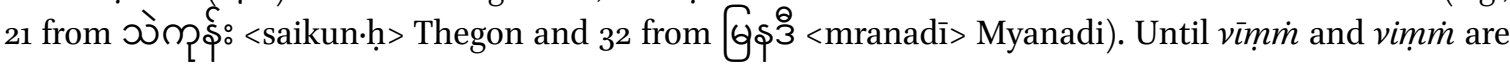
glossed, it is unclear whether they comprise a minimal pair. Even if they did represent two different morphemes, the long vowel may have been an orthographic device to distinguish two homophonous morphemes rather than part of a digraph for long /ï/.

8.2.1.2 um

um occurs in only four akșaras:

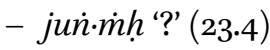

- duk.m'?' (64.7); cf. duk.ṃ 'time' (16.1C)

- mvumin'?' (17.8)

- tdumं'?' (25.7); cf. tdum 'water' (7.18)

In all four cases, the anusvāra may be an error for a subscript dot. Two akșaras have near-homographs with subscript dots. $d u k \cdot \dot{m}$ is almost certainly an error for $d u k \cdot m$ 'time' since it is preceded by rla 'month'. Unfortunately, the context of tdum is not understood, so I am not sure if it is an error for tdum /t.ðu/ 'water'. Although the other two akșaras lack subscript-dotted counterparts †jun். $m h$ and $\dagger m v u m \underline{h}$, I would

17 De Bray (1980:114) describes the Ukrainian reflex of Common Slavic * $i$ as a "fronted $i$ ", but I follow (Shevelov 1993:949) who regards it as a "central front mid vowel" [I]. 
rather not reconstruct a vowel phoneme solely to account for akșaras that could be interpreted in terms of other phonemes as /jun / and /m.vuh/.

8.2.1.3 $\bar{u} \dot{m}$

$\bar{u} \dot{m}$ occurs solely in $p \bar{u} r \cdot \dot{m} h$ '?' (32.5). This spelling is doubly strange, as anusvāras normally accompany neither long vowels (with one exception; §8.2.1.1) nor labial vowels (see §8.2.1.2, 8.2.1.5, 8.2.1.6 for exceptions).

If what Griffiths et al. (2017a) read as $p \bar{u}$ is actually a similar-looking akșara ${ }^{\circ} a$ which is surprisingly

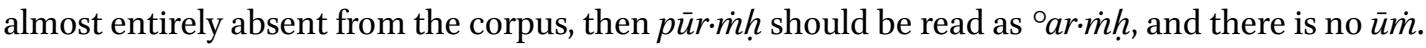

\subsubsection{4 eim}

em occurs only in del.ṃm $\dot{m}$ '?' (16.4A) and kdlem $\dot{h}$ '?' (144) which may be errors for del.ṃh '?' (32.5) and kdleh '?' (145). That explanation cannot be verified until both pairs of akșaras are glossed.

The scribe of del.mim $\grave{h}$ may have accidentally written a superscript dot before adding the correct subscript dot. Given how that scribe spelled /päh/ 'to give' as both paṃh and [peh] in the same inscription (§8.1.6.1), he could have confused /ä/ and /e/ again and written dal.mimh before adding an $e$ symbol to approximate the correct spelling in 32.5 .

kdlem $\grave{h}$ is the only akșara in inscription 144 (a brick), so its anusvāra cannot be influenced by any neighboring akșaras. That dot is irregularly shaped compared to those of the dots of the visarga above it; it may simply be damage.

\subsubsection{5 óm}

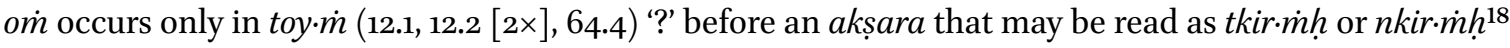
'?'. toy (12.1, 20.3, 32.4, 32.7, 64.2) without an anusvāra occurs in the same context. toy.m and toy. probably represent the same syllable unless 12 and 64 contain a play on words. Although it is possible that the

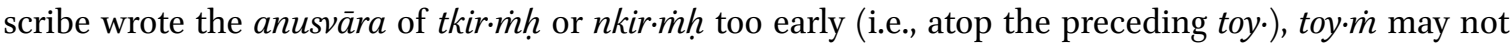
be an error since it occurs independently in two texts. Nonetheless I remain reluctant to posit an eighth vowel phoneme /ö/ solely for a single syllable. ${ }^{19}$ Anusvāra may have a variety of functions in Pyu as it does in modern Mon (§2), so it might represent something other than a vowel quality in toy. $\dot{m}$.

\subsubsection{6 aum}

aum occurs only in sauṃh '?' (56) and slaun்.m '?' (158). Both akșaras are preceded by akșaras with anusvāra $\left(t i(\dot{m})^{20}\right.$ and bay $\dot{m} h \underline{h}$ dhiy. $\left.\dot{m}\right)$, and the scribe may have accidently carried over the anusvāra onto the following akșaras. Unfortunately, there are no attested akșaras †sauh and $\dagger$ slaun. which could confirm that hypothesis.

$18 t$ and $n$ are often difficult to distinguish in the Pyu script.

19 The symbol /ö/ is by analogy with the symbols /ä ï/ for the other vowels written with anusvāra.

20 The anusvāra may be missing from the second akșara of tdam ti due to a lack of space. I supplied it in parentheses on the basis of the collocation tdal.m tim $(32.4[2 \times])$ which would appear as $\dagger$ tdam tim in 56 , a text without final subscript consonants. 
8.2.2 $\quad r$ and $r i$

A literal interpretation of $r$ as syllabic / $r$ / as in Sanskrit is highly unlikely. I do not know of any Southeast Asian language with syllabic liquids. The spelling pri (32.5) with two vowel symbols $(r$ and $i$ ) implies that $r$ was /ri/ in at least some contexts. $r$ could not always have been /ri/ because it also alternates with $i r \cdot \dot{m}$ /ïr/ in the collocation tr hnam. $(64.6,64.8) \sim$ tir.m hnam. $(20.1[3 \times], 20.2,20.3)$. Thus $r$ had at least two phonemic values, /ri/ and /ir/. Phonotactics can sometimes help to determine the intended value of $r$. If $r$ appears before a subscript final consonant, it must be /ri/ or, when preceded by $h, /$ ri $/{ }^{21}$ : e.g., if an akșara for a closed syllable with an uncertain vowel (27.6) is to be read hrm . rather than hum , the spelling must have represented /rim/ rather than $\dagger /$ hïrm/ since the latter contains an impermissible final consonant cluster $(\$ 5)$.

If $r$ appears after a consonant cluster, it must be /ïr/: e.g., $k p r$ '?' (32.9) is /k.pïr/ because †/k.p.ri/ would have two preinitials which would violate Pyu phonotactics $(\$ 5)$.

It is not possible to determine which value $r$ had in open syllables without consonant clusters and known alternate spellings: e.g., $n r$ '?' (32.9, $32.10[2 \times])$ may be either/nri/ or /nïr/ since it has no alternate spellings †nri /nir/, †nri/nri/, or †nir.m /nïr/.

\subsection{3 ai}

ai only appears in Indic loanwords, the village name rabai (7.20 and 8.21) corresponding to Old Mon and Old Burmese rapāy., and Late Pyu chai 'to pour' (7.22, 8.23), possibly another spelling of Late Pyu cha $/ \mathrm{c}^{\mathrm{h}} \mathrm{a}(\mathrm{C}) /$ 'to pour' $(7.10,8.10)$. The correspondence of Pyu ai to Old Mon and Old Burmese $\bar{a} y$. suggests that ai was another spelling of $/ \mathrm{aj} /$. If that is correct, then the coda of $c h a / \mathrm{c}^{\mathrm{h}} \mathrm{a}(\mathrm{C}) /$ must be $/ \mathrm{j} /$.

\section{$9 \quad$ Codas}

As with vowels, the situation with codas is simple: they are either accepted or rejected. The inventory of codas, however, is large, and their relationship to the script is not quite one to one.

\subsection{The problem of missing final subscript consonants}

The greatest unsolved mystery of the Pyu script is why final subscript consonants for codas were not always written. The most baffling case is that of inscription 8: lines 2 and 3 have final subscript consonants, but all other lines do not. Inscription 55 b may contain abbreviated spellings baimh $\sim$ bam $\dot{m} h$ of the honorific bay.mị / bäj/ without final subscript consonants alongside other words with final subscript consonants. All other texts seem to either have final subscript consonants or lack them entirely, though it is impossible to be certain because I am unable to determine whether those consonants are missing in most cases. Inscription 7 is basically identical to 8 apart from the complete absence of final subscript consonants. Final subscript consonants can be both present and absent in texts from the same area: e.g., in inscription 1 from Halin, the honorific is bay.m. h, but in inscription 17 , also from Halin, it is baimh.

Since almost no texts can be dated, it is not possible to say that there was an unwritten final subscript consonant phase followed by a written final subscript consonant phase or vice versa. Even if one could

21 The Pyu phoneme $/ \mathrm{r} /$ is a voiceless $/ \mathrm{r} /$ rather than a syllabic $/ \mathrm{r} /$ as in Sanskrit. 
establish such phases, one would still have to explain the mixture in inscription 8 which may be one of the last known texts.

No molded tablets have final subscript consonants. I hypothesize their absence on tablets is due to a desire to conserve space on a small surface: e.g., inscription 78 is only $8.3 \mathrm{~cm}$ high and $6.8 \mathrm{~cm}$ wide. In theory the formulaic nature of molded tablet texts would help to disambiguate syllables written without final subscript consonants, but the surviving tablets in fact are quite diverse in vocabulary, possibly due to the inclusion of many personal names.

Space cannot, however, be a consideration for the omission of final subscript consonants in the singleline inscriptions on huge urns (2-6) which have an enormous amount of blank space available for such consonants. One urn has a five-line inscription (20) with final subscript consonants.

Complicating matters further is the fact that the Pyu lexicon is almost completely unknown at this point. There are words such as tru 'six' (4) that are only securely identified in texts without final subscript consonants. Other Sino-Tibetan languages have final velar stops in 'six' (e.g., Old Burmese khrok., Old Tibetan drug, and Japhug kutşy < Proto-rGyalrongic *kətrok [Jacques 2004:294]), so truk· '?' (20.1) looks like it may be a spelling of the same word with a final subscript consonant, but it would be premature to equate truk . with tru 'six' until its context is understood. It is often not possible to identify whether short texts are missing final subscript consonants or not if none of their words have been securely identified in texts with final subscript consonants.

In any case, Griffiths et al. (2017b:84-88) demonstrate that the final subscript consonants must represent codas. I will demonstrate that in some cases they represent parts of codas $(\$ 9.2 .2 .2)$ or root-final codas that may have been silent (\$9.2.2.3).

Conversely, does the absence of final subscript consonants represent the reduction and/or loss of

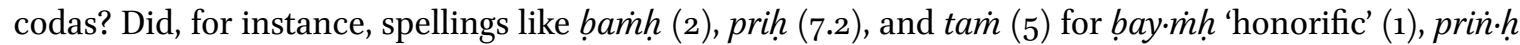
'city' (8.2), and tak·m 'one' (16.1d) reflect how / bäj p.rị̊ täk/ had become / Gäh p.rĩh tä?/ or / Gäh p.rih tä/ or even / bä p.ri tä/ with tones?

Pyu orthography seems to have been relatively stable over a long period, so the presence of final subscript consonants in a late inscription (8) is not necessarily evidence for the retention of codas in the $12^{\text {th }}$ century. Late Pyu could have been like its distant relative Tangut which had lost all stop and nasal codas by the $11^{\text {th }}$ century (Miyake 2012:255, Jacques 2014:206).

On the other hand, the neighbors of Late Pyu - Old Mon and Old Burmese - had codas, so there was little or no areal pressure on Pyu to reduce or lose codas. Late Pyu may have developed tones to compensate for the loss of voiceless sonorant codas absent in Old Mon and Old Burmese, but if it had lost final stops or merged them into a glottal stop centuries before a similar merger in Burmese, those changes could not be due to the influence of its prominent neighbors.

Pyu may have been influenced by unknown neighbors. The extent of linguistic diversity in the Pyuspeaking region is unclear. The relative stability of Pyu orthography over space and time may be suggestive of a literary language that may not have been shared by everyone under Pyu rule. It is theoretically possible that some short Pyu-script texts without any known Pyu morphemes may be in otherwise unattested non-Pyu languages. (All long Pyu-script texts do contain known Pyu morphemes and are therefore probably in Pyu.)

Those hypothetical unknown neighbors were not literary languages and could not have influenced the choice to not write final subscript consonants. There is, however, a distant areal parallel in the Indic scripts of the Philippines as discussed by Griffiths et al. (2017b:150). Although Philippine languages are rich in codas, those codas were not written in Indic scripts until contact with the Spanish. Moreover, the practice of writing codas with virāma symbols to cancel inherent vowels never became popular in 
Philippine scripts. The corpus in the traditional scripts of the Philippines demonstrates that an absence of written codas does not entail an absence of spoken codas. Thus spellings such as prị (7.2) for prin.h 'city' (8.2) are not necessarily evidence for the loss of codas in Pyu.

Yet it is also true that Late Pyu spellings such as prin. $h$ are not necessarily evidence for the retention of codas in Pyu up into the $12^{\text {th }}$ century. One might erroneously conclude that native Burmese words still have final /k y c n t n p m j/ on the basis of their spellings with "killed" consonants $<k \cdot \dot{n} \cdot \mathrm{c} \cdot \tilde{n} \cdot \tilde{n} \tilde{n} \cdot \mathrm{t} \cdot \mathrm{n} \cdot \mathrm{p} \cdot$ $\mathrm{m} \cdot \mathrm{y} \cdot>$ in the $2 \mathrm{~s}^{\mathrm{st}}$ century script; only spelling errors might lead one to suspect there had been mergers. Knowledge of the Pyu lexicon has not yet advanced to the point where one can say, for instance, that ${ }^{\circ} i p$. '?' (32.2) is an error for 'ik. 'one' (16.1A) and hence evidence for the merger or loss of final /k p/.

Unable to determine how Pyu codas changed over time, my policy is to always phonemicize codas indicated by final subscript consonants even if they are not always indicated in spelling: e.g., I phonemicize both $\operatorname{tam}(5)$ and $\operatorname{tak} \cdot \dot{m}$ (16.1d) for 'one' as /täk/. I can only do that if I am certain two spellings represent the same morpheme. If I am not certain, then I can only phonemicize on the basis of each spelling: e.g., tru 'six' (4) is /t.ru/ but not /t.ruk/ because I do not know for sure if truk. '?' /t.ruk/ (20.1) is a spelling of the same word.

\subsection{Accepted codas}

Pyu has two classes of codas: those written with visarga and those written without it. The latter are what I call 'simple codas' (\$9.2.1); their interpretation is straightforward. The former (\$9.2.2) are more difficult to interpret.

9.2.1 Simple codas

There are ten simple codas (Table 7 ). All are written with final subscript consonants. These codas are often not written in Pyu texts.

TABLE 7 Pyu simple codas and their spellings

$\begin{array}{lll}k \cdot / \mathrm{k} / & \dot{n} \cdot / \mathrm{g} / & \\ & & y \cdot / \mathrm{j} / \\ & r \cdot / \mathrm{r} / \\ t \cdot / \mathrm{t} / & n \cdot / \mathrm{n} / & l \cdot / \mathrm{l} / \\ p \cdot / \mathrm{p} / & m \cdot / \mathrm{m} / & v \cdot / \mathrm{w} /\end{array}$

A reviewer notes that "the codas are exactly those one would expect from a Tibetan or Kiranti perspective. The only 'missing' coda would be -s (which may have changed into visarga)." I would also add that, from a Tibetan perspective, /Cs/-cluster codas are also missing.

The palatal codas / $\mathrm{n} /$ found in Old Mon and Old Burmese are absent from Pyu.

I interpret $v \cdot$ as $/ \mathrm{w} /$ as in Old Mon and Old Burmese. Regardless of its precise phonetic value, it belongs to the class of oral sonorants.

9.2.2 Codas written with visarga

All final subscript consonants other than $p$. may be followed by visarga (§9.2.2.2-§9.2.2.3). Visarga may also occur without a preceding final subscript consonant (\$9.2.2.1). All spellings of codas with visarga are in Table 8. Alternate interpretations are in parentheses. 
TABLE 8 Pyu codas written with visarga

$h, k \cdot h, t \cdot h / \mathrm{h} /(/ 2 / ?)$

\begin{tabular}{|c|c|}
\hline & $y \cdot h / \mathrm{j} /\left(/ \mathrm{j}^{2} / ?\right)$ \\
\hline & $r \cdot h / \mathrm{r} /\left(/ \mathrm{r}^{?} / ?\right)$ \\
\hline$n \cdot h / \mathrm{n} /\left(/ \mathrm{n}^{?} / ?\right)$ & $l \cdot h / \mathrm{l} /\left(/ l^{P} / ?\right)$ \\
\hline$m \cdot h / \mathrm{m} /\left(/ \mathrm{m}^{2} / ?\right)$ & $v \cdot h / M /\left(/ \mathrm{w}^{2} / ?\right.$ \\
\hline
\end{tabular}

\subsubsection{Visarga without a preceding final subscript consonant}

I interpret $h$ as $/ \mathrm{h} /$ as in Sanskrit, Old Mon, and Old Khmer. However, there is no guarantee that the Pyu used an Indic symbol in an Indic manner. If, for instance, the Pyu had a final glottal stop like Old Chinese but no final /h/, they might have pronounced visarga in heavily accented Sanskrit as their only glottal / $/$, and they might have written their native coda $/ \mathrm{R} /$ as $\underline{h}$ as the Thai and the Christian Sgaw Karen (Katō 2018:29) did centuries later. Perhaps some Pyu dialects had one final glottal consonant while some had the other. Perhaps the two glottals were allophones in complementary distribution. Perhaps the glottal coda conditioned phonation or a tone before disappearing at some point in speech while remaining in writing. The visarga in the Late Pyu borrowed names vrahmadamyoh (8.15) and samanardommị (8.20) does not correspond to an /h/ in Sanskrit brahmadeva ${ }^{22}$ and Old Mon sak.munalor. (7.25), suggesting that it may have represented a suprasegmental by the $12^{\text {th }}$ century. If one prefers to keep those multiple possibilities in mind, this coda could be written as $/ \mathrm{H} /$ to avoid committing to a phonetic interpretation.

Visarga may go back to the *-s coda that is 'missing' from a Tibetan or Kiranti perspective (\$9.2.1).

A reviewer suggests that visarga may have even more complex sources, pointing out that the Kiranti language Khaling has $-s$ from *-ksu: e.g., mos 'bear' < *moks < *moksu (Jacques 2016:56-57); cf. Dumi mo:kst 'id.' (Van Driem 1993:399). However, there is no evidence so far for vocalic apocope in Pyu.

For *stop-s sequences as possible sources of visarga, see §9.2.2.3.

\subsubsection{Voiceless sonorants or checked sonorants}

I interpret sequences of final subscript sonorant characters and visarga as voiceless sonorants: e.g., $\dot{n} \cdot h \mathbf{h} / \mathfrak{y} /$. But they may have been voiced sonorants like Kri $/ V^{2} \mathrm{n}^{2} \mathrm{j}^{2} \mathrm{n}^{2} \mathrm{~m}^{2} \mathrm{j}^{2} \mathrm{r}^{2} \mathrm{l}^{\mathrm{P}} \mathrm{w}^{2} /$ with what Enfield and Diffloth (2009:19) described as "checked terminance": i.e., "with full obstruction of airflow and without immediate release". All of those sonorants with checked terminance with the exception of $/ \mathrm{n}^{\mathrm{P}} /$ may have existed in Pyu if visarga is interpreted as a glottal stop.

Enfield and Diffloth (2009:16) also note the presence of "devoiced" oral sonorant codas in Kri like those that I reconstruct for Pyu: $/ V_{0}^{\circ} \mathrm{r}_{0} \mathrm{M} / .{ }^{23} \mathrm{Kri}$, however, lacks the devoiced nasal codas that I also reconstruct for Pyu: / $\eta_{0} \mathrm{n}_{\mathrm{o}} \mathrm{m} /$. Such codas may have been in Early Middle Chinese; they would correspond to the nasals with final aspiration reconstructed by Pulleyblank (1991): * $\mathrm{y}^{\mathrm{h}}{ }^{*} \mathrm{n}^{\mathrm{h}} * \mathrm{~m}^{\mathrm{h}}$.

\footnotetext{
22 The nominative singular of brahmadeva is brahmadevah with a final /h/, but the visarga of Pyu probably does not reflect that $/ \mathrm{h} /$, as there is no other case of the Pyu retaining the visarga of a nominative singular.

23 Enfield and Diffloth's voiceless vowel /V/ corresponds to a vowel-glottal coda sequence /Vh/ in my analysis of Pyu. I have rewritten their $/ \mathrm{w} /$ for Kri as $/ \mathrm{M} /$ to facilitate comparison with my phonemic symbols.
} 
In Kri, sonorant codas with checked terminance contrast with voiceless sonorant codas, whereas no such distinction can be reconstructed for Pyu (Table 9). Written Pyu may have had one or the other type of sonorant coda, though perhaps some dialects had an Early Middle Chinese-like distinction between the two that was lost in the literary language which favored only one.

TABLE 9 Sonorant coda types in Pyu, Kri, and Early Middle Chinese

\begin{tabular}{lcccc}
\hline Sonorant coda type & $\begin{array}{c}\text { Pyu (if } h=/ \mathrm{h} /, \\
\dot{n} \cdot h / \mathrm{\eta} / \text {, etc. })\end{array}$ & $\begin{array}{c}\text { Pyu }(\text { if } h=/ \mathrm{l} /, \\
\left.\dot{n} \cdot h / \mathrm{\eta}^{2} / \text {, etc. }\right)\end{array}$ & Kri & Early Middle Chinese \\
\hline Devoiced nasal & $\checkmark$ & $\times$ & $\times$ & $\checkmark$ \\
Devoiced oral & $\checkmark$ & $\times$ & $\checkmark$ & $\checkmark$ \\
Checked terminance & $\times$ & $\checkmark$ & $\checkmark$ & $\checkmark$ \\
\hline
\end{tabular}

I reconstruct unit phonemes for Pyu codas (e.g., $/ \stackrel{\circ}{\mathrm{y}} /$ or $\left./ \mathrm{y}^{?} /\right)$ rather than clusters $($ e.g., $/ \mathrm{gh} /$ or $/ \mathrm{y}$ ? $/$ ) in any scenario. Final clusters would be typologically unusual in Southeast Asia, and /h/-final clusters like /yh/ would be typologically unusual on a global scale. Moreover, unit phonemes not only simplify the syllable structure $(\$ 5)$ but also allow me to recycle the voiceless sonorants I already posited for initials (Table 5). Even if Pyu had sonorant codas with checked terminance rather than voiceless sonorant codas, I could regard the former as positional allophones of voiceless sonorant phonemes: e.g., / $\mathfrak{y} /$ would be [门๋] as an initial but $\left[\mathrm{y}^{2}\right]$ as a final. On an abstract level, Pyu had only two types of sonorants in both initial and final positions: plain and marked. The marked sonorants would have become plain if Pyu had developed phonemic phonation or tones to compensate for their loss at some point after the creation of the $\operatorname{script}(\$ 10)$.

\subsubsection{Stop-visarga sequences}

There are two such sequences $(k \cdot h$ and $t \cdot h)$ in 14 akșaras which appear a total of 15 times in 8 texts $(16,20$, $21,22,25,30,32,64)$.

- tḅak.m. '?' (20.5); cf. tḅamh '?' (2)

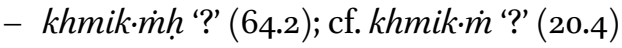

- dok.h '?' (20.4); cf. doh '?' (25.1)

- tduk.h '?' (20.5)

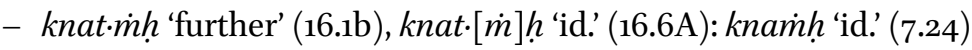

- nat.h '?' (30.1); cf. nat. '?' (20.5) and nah '?' (39.5)

- nrat. $h$ '?' (20.4)

- pat.m் (21.4); cf. pam h 'to give' (7.5) and Old Chinese 界 *pi[t]-s 'to give'

- rat.h '?' (32.5); cf. rat. '?' (32.5) and rah '?' (84.1)

- ${ }^{\circ} a t \cdot \dot{m} h$ '?' (25.7)

- kit.m. '?' (20.1)

- tnit.m.̣ '?' (22.7)

- pit.m.

- nrut.h '?' (32.10)

The sequence $p \cdot h$ is not attested. This is not surprising since $p$. is the least common of the three possible final stops in Pyu. 
Although one might interpret those sequences as $/ \mathrm{k}^{\mathrm{h}} \mathrm{t}^{\mathrm{h}} /$ or $/ \mathrm{k}^{\mathrm{t}} \mathrm{t}^{\mathrm{P}} /$ depending on whether $h$ is $/ \mathrm{h} /$ or $/ \mathrm{R} /$, final aspirates and glottalized stops are typologically unusual in Southeast Asia. Moreover, final aspirates might have been written with final subscript aspirate characters $(\dagger k h \cdot$ and $\dagger t h \cdot)$ rather than with final subscript unaspirated characters followed by visarga $(k \cdot h$ and $t \cdot h)$.

The history of Chinese may provide a key to the interpretation of those sequences. Haudricourt (1954:364) proposed that Old Chinese, like Old Tibetan, had final clusters combining root-final stops with sibilant suffixes: e.g.,

學 *m-k'ruk 'to study' > 斆 *m-k'ruk-s ‘to teach' (Baxter \& Sagart 2014a:59)

In Middle Chinese, those clusters were later reduced to the 去聲 qùshèng 'departing tone' (indicated by $H$ in Baxter and Sagart's notation $\left.{ }^{24}\right)$ :

學 Old Chinese * $\mathrm{m}-\mathrm{k}^{\varsigma}$ ruk > Middle Chinese haewk 'to study'

斆 Old Chinese *m-k'ruk-s > Middle Chinese haewH 'to teach'

In that particular case, an Old Chinese alternation between ${ }^{*} \mathrm{k}$ and ${ }^{*} \mathrm{k}$-s became a Middle Chinese alternation between $k$ and $H$ in Baxter and Sagart's notation.

Similarly, a pre-Pyu alternation between ${ }^{*} \mathrm{k}$ and ${ }^{*} \mathrm{k}$-s could have become a Pyu alternation between $k$. and $h$. Sporadic spellings like $k \cdot h$ may be morphophonemic: the $k$. indicates the lost root-final *k and the $h$ reflects the remaining final glottal (or phonation or tone derived from that glottal). This type of rootpreserving spelling is found in Korean: e.g., /nok/ 'spirit' is spelled 넜 <nŏks $>$ with a silent $入<\mathrm{s}>$ that is pronounced when a vowel-initial suffix follows: e.g., 넚을 <nŏks.ŭl > v[noksul] 'spirit.ACC'.

There are six problems with the morphophonemic hypothesis.

First, the evidence for a suffix $-\underline{h}$ is extremely weak. There is only one known word family which may contain such a suffix:

- se 'to make' (7.10, 7.12, 7.19, 8.10, 8.12, 8.19)

- saimh 'to do' (7.20, 8.20, 16.2C, 16.5C; Griffiths et al. 2017b:135)

- tsaimh 'deed' (16.2C, 16.5C; Griffiths et al. 2017b:122-123)

The $e$ in se may reflect a merger of /e/ and /ä/ in the speech of the scribe. sam '?' (6o) may be the etymologically correct spelling if it is the same word.

Second, there is only one securely glossed set of akșaras with and without a stop before visarga:

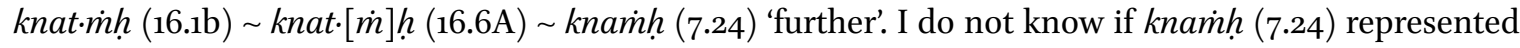
/knät/ or / knäh/ since it appears in a text without final subscript consonants. The status of other proposed sets is uncertain: e.g., dok.h '?' (20.4) and doḥ '?' may or may not be two spellings of the same morpheme $/$ doh $/<$ *dok-s.

Third, not all akșaras with stop-visarga sequences have near-lookalikes without a stop or visarga.

Fourth, some near-lookalikes with visarga are in texts without final subscript consonants (39 and 84). If 39 and 84 had been written with final subscript consonants, $\dot{n} a h^{\prime}$ '?' (39.5) and raḥ '?' (84.1) might have been written as $\dot{n} a t \cdot h$ and rat.h or with different final subscript consonants: e.g., as nak.h and rav $\cdot h$, etc.

24 Baxter and Sagart's (2014a:12) Middle Chinese notation is italicized rather than starred because it is "not intended as a phonetic reconstruction" (italics as in original). 
In other words, they may not be evidence for reading nat. ' '?' (30.1) and rat.h '?' (32.5) as / $\mathrm{yah} /$ and /rah/.

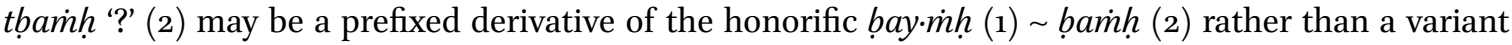

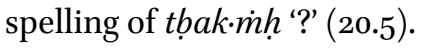

Fifth, the evidence does not strongly support Korean-style 'Cheshire cat' consonants that appear and disappear depending on the environment. In theory, a root-final stop might survive before homorganic

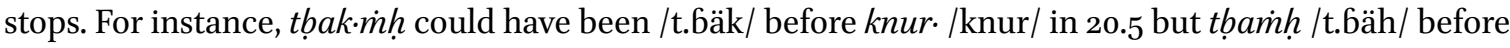

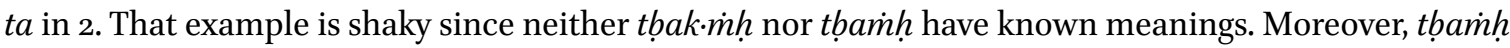
appears in a text without final subscript consonants; tọamh may have had an unwritten consonant that was not $/ \mathrm{k} /$.

Lastly, only four out of fifteen $C \cdot h$ appear before homorganic stops. If root-final stops survived before any stop, and if $/ \%$ was a stop, then I could say that twelve out of fifteen $C \cdot h$ reflect final $/ \mathrm{k} t /$ before stops. I could even inflate that number to thirteen if I could claim that the initial / $/$ became [d] or even $[t]$ after the coda / $\mathrm{t} /$ in knat.m. $h \mathrm{du}[\mathrm{k} \cdot \mathrm{m}] \mathrm{m} / \mathrm{k}$.nat ðuk/ 'future time' (16.1b). I could then regard the two remaining cases as erroneous uses of spellings that would have been appropriate before stops: dok. $h$ before $\dot{n} a v$. (20.4) and nrut.h before ngil.ṃh (32.10). Nonetheless I am not yet able to demonstrate that $C \cdot h$ words generally did not end in stops before nonstops: e.g., that knat.m. 'further' was almost always spelled knam $h$ before fricatives and sonorants.

Could a visarga after a stop be an error - an accidental carryover from a visarga in the previous akșara or a premature visarga belonging to the next akșara? The visarga carryover error hypothesis cannot account for knat.m $h$ 'further' which is written with a visarga twice regardless of whether its neighbors have visargas (16.6A) or not (16.1b). Eight of the fifteen $C \cdot h$ akșaras have neighbors without visargas, and a space separates $\dot{n} a t \cdot h$ from gay. $\dot{m} h$ ' I' (30.1), so the latter is unlikely to have been an influence on the former. One could argue that, for instance, tḅak.ṃ knur. (20.5) is an error for $\dagger t b a k \cdot \dot{m} k n u r \cdot h$ with a misplaced rather than a duplicated visarga, but no such sequence exists.

Conversely, perhaps the visarga after a stop is correct, and the stop is an error influenced by a stop in a neighboring akșara. But there is only a single case in which a stop in a $C \cdot h$ combination matches a neighboring stop. $t d u k \cdot h$ has a $k$. like the tdrak. '?' that follows it, but $t d u k \cdot h t d r a k$. looks like a semialliterative, semi-rhyming sequence. The stop carryover error hypothesis is even less convincing than the visarga carryover error hypothesis.

If $h$ represented a final glottal stop as in Thai or Christian Sgaw Karen script (Katō 2018:29), it could represent the reduction of $/ \mathrm{k} t /$ to [?]. Spellings like $\dot{n} a t \cdot h$ could be compromises between a phonetic spelling $\dot{n} a h$ and an etymological spelling nat retaining the original stop. The trouble with this hypothesis is that it cannot be tested until sets of akșaras such as $\dot{n} a t \cdot h, \dot{n} a h$, and $\dot{n} a t \cdot$ are defined. That trio could turn out to be three unrelated words rather than three spellings of the same word.

My last hypothesis is that $h$ had become a tonal marker by the time inscriptions 20, 30, and 32 were written, and that $d o k \cdot h$ and the like were borrowings of stop-final syllables with tones written as $h$ that did not normally develop in native stop-final syllables: cf. Thai "dead" (i.e., stop-final) syllable borrowings with anomalous tones such as กอล์ฟ [ko:p1] 'golf'. ${ }^{25}$ However, no stop-visarga akșaras have any known foreign sources. Also, at present only a single potential non-Indic loanword (tha 'golden' < Old Mon

25 Normally only a low tone would be possible in a Thai syllable like [ko:p] beginning with [k] and ending in a stop. In the case of 'golf', the anomalous tone is not indicated in the Thai script, whereas I am hypothesizing that an anomalous tone was sporadically written in the Pyu script. 
$<$ thar.> 'gold'; 7.10, 8.10, etc.) is known, so it is hazardous to posit fourteen different loans with aberrant tones from unknown sources.

Xun Gong (p.c.) speculates that $h$ indicated breathy phonation: e.g., knat. $\dot{m} h \underline{\text { was }} / \mathrm{k} . n$ ặt/. His solution has two enormous advantages over mine. First, it is far simpler than my morphophonemic explanation for stop-visarga sequences. Second, it eliminates the need to posit a series of voiceless sonorant codas. Gong would interpret nhom.h 'three' (20.1) as /n.họm/ with a final voiced /m/ rather than as /n.hom/ with a final voiceless $/ \mathrm{m} /$.

Gong suspects that this breathy phonation is inherited from Proto-Sino-Tibetan. That would account for why Pyu $h$ occurs with both voiced and voiceless initials. Pyu breathiness was unlike modern Mon breathiness that was conditioned by voicing in Old Mon initials.

But why is $h$ so rare in Pyu stop-final syllables? Gong hypothesizes that original breathy phonation was lost in stop-final syllables; the breathy phonation in a handful of stop-final syllables is the result of stop suffixes added to open syllables ending in vowels with breathy phonation: e.g., doh (25.1) is the root of dok.h / dọk/ (20.4) < *do-k. However, there is no evidence of stop suffixes in Pyu, and the meanings of pairs like doh and dok.h are unknown: doh may bear no semantic resemblance to $d o k \cdot h$.

At present I cannot decide what to do with akșaras such as dok.h. I can only provide two possible phonemicizations for each akșara, one ending in a stop and the other ending in a glottal: e.g., /dok/ /doh/. I will not posit special codas or coda clusters to account for rare stop-visarga sequences.

\subsection{Rejected coda}

The only coda that does not fit into the above scheme is the double final subscript consonant sequence $r \cdot r \cdot$ which is only in rlar.r. (55a). A single instance is not sufficient to posit another rhotic phoneme /R/ or a final geminate $/ \mathrm{r}: /$, so I regard $r \cdot r$ as an error for $r \cdot / \mathrm{r} /$.

\subsection{Known rhymes}

In Old Mon and Old Burmese, the distribution of vowels and codas was skewed: i.e., not every vowel could precede almost every coda (Shorto 1971: xvii, Nishi 1999:23). On the other hand, there is no such skewing in Pyu (Table 10). It is unclear whether the nearly full system of Pyu rhymes is conservative or the result of changes and/or loans filling in many original holes.

Gaps in the rhyme inventory appear to be largely random: e.g., there is no particular reason why $/ \mathrm{m}_{\mathbf{0}} /$ would not be permissible after /e/ if it follows all other vowels. The discovery of future texts may fill in some of these holes.

Some gaps might correspond to rhymes in closed syllables unique to texts written without final subscript consonants: e.g., kleh in those texts $(3,4,5,6)$ might be / klem/ with the rhyme / em/ unattested in texts with final subscript consonants.

A few gaps might have resulted from sound changes: e.g., *äj *ej, and *äw may have monophthongized to $/ \mathrm{e} /, \mathrm{e} /$, and /o/, whereas final glottals in *äjH, *ejH, and *äwH blocked monophthongization, and those rhymes retained their original vowels as /äj ej äm/. Internal reconstruction (e.g., word families with /e/ /äj/ alternations) and external sound correspondences could confirm that hypothesis.

I consider subscript dots $(m)$ to be diacritics for fricative initials $(\$ 10.8)$ and therefore exclude them from the rhymes in Table 10: e.g., the rhymes $a k \cdot$ and $a k \cdot m$ are both represented in Table 10 as $a k$.

Uncertain rhymes such as $i r \cdot[h]$ are in parentheses.

$r$ is listed twice because it represents both / ri/ and /ïr/ (\$8.2.2). 
TABLE 10 Spellings of known Pyu rhymes

\begin{tabular}{|c|c|c|c|c|c|c|c|}
\hline Coda|vowel & /a/ & |ä/ & /i/ & /ï/ & $/ \mathrm{u} /$ & /e/ & $10 /$ \\
\hline$|\varnothing|$ & $a, \bar{a}$ & $a \dot{m}$ & $\begin{array}{l}i, r / \mathrm{ri} /,{ }_{0} i / \\
\mathrm{ri} /\end{array}$ & $i \dot{m},(\bar{\imath} \dot{m} ?)$ & $u, \bar{u}$ & $e$ & $o, a u$ \\
\hline$/ \mathrm{k} /$ & $a k \cdot,(a k \cdot h ?)$ & $\begin{array}{l}a k \cdot \dot{m} \\
(a k \cdot \dot{m} h ?)\end{array}$ & $i k$ & $i k \cdot \dot{m}$ & $u k \cdot,(u k \cdot h ?)$ & $e k$. & $\begin{array}{l}o k \cdot, a u k \cdot, \\
(o k \cdot h ?)\end{array}$ \\
\hline$/ \mathfrak{y} /$ or $/ \mathrm{y}^{2} /$ & $a \dot{n} \cdot h$ & $a \dot{n} \cdot \dot{m} h \underline{h}$ & $i \dot{n} \cdot h$ & $i \dot{n} \cdot \dot{m} h$ & $u \dot{n} \cdot h$ & $e \dot{n} \cdot h$ & on $\cdot h$, aun $\cdot h$ \\
\hline$|\mathrm{n}|$ & $a \dot{n}$ & $\bar{a} \dot{n} \cdot \dot{m}, \bar{a} \dot{n} \cdot m$ & $i \dot{n}$ & $i \dot{n} \cdot \dot{m}$ & $u \dot{n}$ & $e \dot{n}$ & 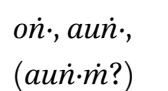 \\
\hline$|t|$ & at., (at.h??) & $a t \cdot \dot{m}$ & $i t$ & $\begin{array}{l}i t \cdot \dot{m}, \\
(i t \cdot \dot{m} h ? ?)\end{array}$ & $u t \cdot,(u t \cdot h ?)$ & et. & ot., aut. \\
\hline$/ \mathrm{n} /$ or $/ \mathrm{n} /$ & $a n \cdot h$ & $a n \cdot \dot{m} h$ & $i n \cdot h$ & $i n \cdot \dot{m} h$ & $u n \cdot h$ & $e n \cdot h$ & on $\cdot h$ \\
\hline$/ \mathrm{n} /$ & $a n$. & $a n \cdot \dot{m}$ & in. & $i n \cdot \dot{m}$ & un. & en. & on $\cdot$, aun. \\
\hline$/ \mathrm{p} /$ & ap. & $a p \cdot \dot{m}$ & ip. & $i p \cdot \dot{m}$ & up. & $x$ & op $\cdot$, aup. \\
\hline $\begin{array}{l}/ \mathrm{m} / \text { or } \\
/ \mathrm{m}^{2} /\end{array}$ & $a m \cdot h$ & $a m \cdot \dot{m} h$ & $i m \cdot h$ & $i m \cdot \dot{m} h$ & $u m \cdot h$ & $x$ & om $h$ \\
\hline$/ \mathrm{m} /$ & am. & $a m \cdot \dot{m}$ & $\begin{array}{l}\mathrm{im} \cdot,(\mathrm{hrm} \cdot \\
/ \mathrm{R} \operatorname{im} / ?)\end{array}$ & $i m \cdot \dot{m}$ & um. & em. & om $\cdot$, aum \\
\hline$/ \mathrm{j} /$ or $/ \mathrm{j} /$ & $a y \cdot h$ & ay. $\dot{m} h$ & $i y \cdot h$ & $\dot{i y} \cdot \dot{m} h$ & $u y \cdot h$ & $([e y \cdot] h ?)$ & $x$ \\
\hline $\mid \mathrm{j} /$ & $a y \cdot, a i$ & $\times$ & $i y$. & $i y \cdot \dot{m}$ & $u y$. & $x$ & $\begin{array}{l}\text { oy·, auy. } \\
(\text { oy·m?) }\end{array}$ \\
\hline$/ \mathrm{r} /$ or $/ \mathrm{r}^{2} /$ & $\operatorname{ar} \cdot h$ & ar.m $\dot{m} h$ & $(i r \cdot[h] ?)$ & $\dot{i r} \cdot \dot{m} h$ & $\begin{array}{l}u r \cdot h \cdot \\
(\bar{u} r \cdot \dot{m} h \underline{?} ?)\end{array}$ & $e r \cdot h$ & or $\cdot h$, aur $\cdot h$ \\
\hline$|\mathrm{r}|$ & $a r \cdot, a r \cdot r$ & & $i r$ & $i r \cdot \dot{m}, r$ & $u r$ & $e r$ & or, aur. \\
\hline$/ 1 /$ or $/ l^{2} /$ & $a l \cdot h$ & al.minh & $i l \cdot h$ & $i l \cdot \dot{m} h$ & $u l \cdot h$ & $\begin{array}{l}e l \cdot h, \\
(e l \cdot \dot{m} h ?)\end{array}$ & $o l \cdot h$, aul $\cdot h$ \\
\hline$/ 1 /$ & $a l \cdot$ & $a l \cdot \dot{m}$ & $i l$. & $i l \cdot \dot{m}$ & $u l$. & el. & ol: aul. \\
\hline $\mid \mathrm{M} /$ or $/ \mathrm{w}^{\mathrm{P}} \mid$ & $a v \cdot h$ & $a v \cdot \dot{m} h$ & $i v \cdot h$ & $x$ & $x$ & $x$ & $o v \cdot h$ \\
\hline$|\mathrm{w}|$ & $a v$ & $x$ & $i v$ & $i v \cdot \dot{m}$ & $u v$ & $e v$ & $o v$ \\
\hline$/ \mathrm{h} /$ or $/ \mathrm{P} /$ & $\begin{array}{l}a h, \bar{a} h(a k \cdot h, \\
\text { at.h? })\end{array}$ & $\begin{array}{l}a \dot{m} h, \\
(a k \cdot \dot{m} h ?)\end{array}$ & $i h$ & $i \dot{m} h,(i t \cdot \dot{m} h ?$ ?) & $\begin{array}{l}u h, \bar{u} h,(u k \cdot h \\
u t \cdot h ?)\end{array}$ & ,eḥ, (em & $\begin{array}{l}o h,(o k \cdot h ?, \\
\text { auminh?) }\end{array}$ \\
\hline
\end{tabular}

Rhymes with stop-visarga sequences are listed twice in parentheses because their interpretation is uncertain (\$9.2.2.3).

\section{$10 \quad$ Was Pyu a tonal language?}

One characteristic that sets the Pyu script apart from its Indic sisters is the high frequency of dots: the anusvarra, the visarga, and the subscript dot that looks like Written Burmese $633 \hat{n} 6 \hat{\sigma} \tilde{\Phi}<{ }^{\circ} \mathrm{ok}$ mrac $\cdot>$. In modern Burmese, the visarga and $<^{\circ}{ }^{\circ} k^{\cdot}$ mrac $\cdot>$ indicate the high and creaky tones. 
On the basis of correspondences between visargas in Pyu and modern Written Burmese, Blagden (1911:373) wrote,

it also appears highly probable that the visarga symbol is used in this text [the Kubyaukgyi inscription] as a tonal mark; and it seems not unlikely that the Burmese (who did not use it in the parallel [Old Burmese] version [of the Kubyaukgyi]) subsequently borrowed its use as such from the people who spoke the language of our text. This use of the visarga symbol as a tonal mark is confirmed by the proper names in which it occurs. Similarly, the proper names show that the subscript anusvāra can only indicate some slight peculiarity in the pronunciation of a vowel, while a combination of it with an anusvāra symbol placed rather higher and to the right of a letter-group also has some such effect. These are therefore apparently also tonal marks.

Shafer (1943) was the first to propose atonal interpretations of some of the dots. Like Blagden, he saw a parallel between the visargas of Pyu and Old Burmese and projected the falling tone value of the visarga of modern Burmese into both of those languages. However, he proposed that the anusvarra was a glottal stop. He initially hypothesized that the subscript dot indicated short vowels but later rejected that idea after noting the dot's frequent occurrence with $g$ and $d$ in Indic loans.

Luce (1985:63) built upon Blagden's tonal interpretation of the many dots in the Pyu script:

If we may assume that the $-i$ vowel loop will push out an anusvāra to the right, not less than eight types of tonal marks can be distinguished. Possibly there were glottal stops; but there is no clear evidence for this. [...] If we may assume that words with no tonal mark were of medium pitch, perhaps those with anusvära (often ending with $-i$ ) were of high pitch, and those with 'a-myit' [i.e., $<^{\circ} \mathrm{ok}^{\cdot} \mathrm{mrac} \cdot>$ ] (often ending with $-u$ ) were of low pitch. Those with visarga (which means 'release') may have been in the falling tone, medium pitch; in the highfalling tone or the low-falling tone if the visarga is combined with the anusvära or the 'a-myit' respectively. There is one instance where all three are combined: $t v a a_{\text {a }}[=t v a m \dot{m} h /$ t.väh/] 'to elapse'. I can only leave that, I fear, to the reader's imagination.

Luce (n.d. B) proposed a full set of tonal values for dot combinations.

Diller (1996:240-241) argued against a tonal interpretation of the dots on several grounds:

1. "Tibeto-Burmese" [i.e., Tibeto-Burman] languages typically do not have eight tones.

2. Half the Pyu vocabulary is not written with dots, and it would be odd for half the lexicon to belong to one tone class and the rest to belong to others.

3. If Blagden and Luce were right, Pyu would have had the "most complex tone-marking orthography ever employed before the age of technical phonetic transcription".

4. Blagden had posited Pyu tones on the basis of projecting modern Burmese tones back into Old Burmese, unaware of future advances in the understanding of tonogenesis casting doubt on the full tonality of Old Burmese. ${ }^{26}$

26 Diller (1996:238-239) presents arguments against regarding Old Burmese as fully tonal, citing other works in support of his view. 
5. The Pyu script did not have any means to mark codas which must have existed because they are present in Chinese transcriptions of Pyu.

Diller proposed that the dots indicate codas and "semivowel off-glides or diphthongs" or "similar modifications of vowel quality or quantity, perhaps in tandem with on-line signs."

Katō (2005) thought the subscript dot indicated the implosion of stop onsets and the glottalization of glide onsets:

$-g-m={ }^{*} \oint$

- $d-m={ }^{*} \mathrm{~d}$

$-y-\underline{m}={ }^{*} \mathrm{Pj}^{27}$

$-v-\underline{m}={ }^{*} \mathrm{P} w$

In his view, anusvāra also had a double function: it stood for a glottal stop in some words and for vowel nasalization in others.

He did not propose a phonetic value for visarga, but he did observe that it corresponded to Haudricourt's (1975) Proto-Karen tone 2.

Krech (2012) critiqued Shafer in depth but did not provide values for the dots beyond mentioning "serious doubts" about visarga indicating a tone and stating that the subscript dot combines with consonants to indicate unspecified Pyu initials absent from Pali.

Miyake (2017) most recently proposed that the subscript dot indicated a marked phonation which may have been breathy.

I have already posited atonal interpretations of anusvāra (\$8.1.6) and visarga (\$9.2.2), and will discuss the subscript dot in detail in (\$10.8). For now I provide a bird's-eye comparison of most of the above proposals with mine in Table 11.

A tonal and an atonal interpretation of the dots need not be mutually exclusive. Although I am certain that the anusvāra differentiated /ä i/ from /a i/ (§8.1.6.1, §8.1.6.2) and that the subscript dot indicated fricatives (\$10.8), I am open to the possibility of the visarga indicating a tone at a later period when final glottals and voiceless or glottalized sonorants might have conditioned tones. This shift from atonal to tonal would have been concealed by the Pyu script just as it is concealed by the Tibetan script which gives no indication that modern Lhasa Tibetan is tonal. Extending the Tibetan analogy further, different Pyu dialects may have been tonal to different degrees even if their speakers shared a common orthography.

I address the previous proposals in detail in the next seven sections. To avoid redundancy, I only deal with non-overlapping aspects of each proposal.

\subsection{Response to Blagden's proposal}

Blagden was not an Indologist, but he was certainly aware of how Indic scripts worked and must have known that visarga represented final / $\mathrm{h} /$ in Sanskrit. Moreover, as the founder of Old Mon studies, he knew that visarga represented final / $\mathrm{h} /$ in Mon. He must have been constrained by the unspoken assumption that tonal languages were always tonal. If modern Burmese was tonal, then Old Burmese must also have been tonal.

27 I have converted Katō's non-IPA ?y to *?j for consistency with my own IPA-based notation. 


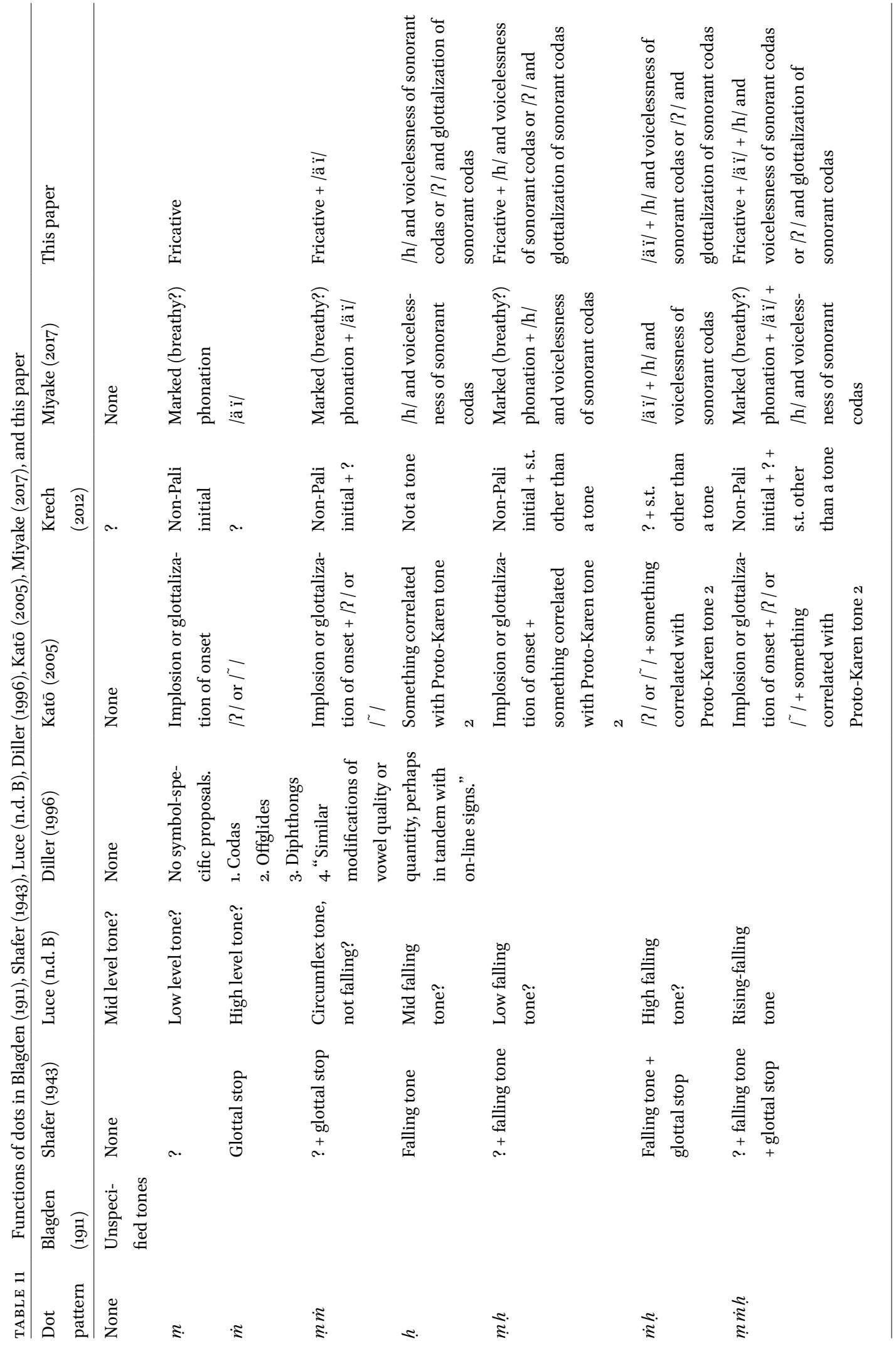


But that is not so; it is now common knowledge that Old Chinese and Old Tibetan were atonal, and, like Diller, I would argue that Old Burmese was not yet fully tonal. Pulleyblank's (1991) reconstruction of Early Middle Chinese circa the sixth century CE - a contemporary of Old Pyu - had glottalized and aspirated finals but no tones unlike modern Chinese languages such as Cantonese which has as many as nine tones depending on the analysis. ${ }^{28}$

Although modern Kra-Dai languages have as many as fifteen tones - again depending on the analysis $^{29}$ - Proto-Hlai had no tones (Norquest 2016). Proto-Tai tones in Chinese loanwords correspond to atonal features in Old and Early Middle Chinese, implying that Proto-Tai may also have had such features. I see no reason why other early Kra-Dai languages could not have had glottal features instead of tones. ${ }^{30}$

Ratliff (2010:192-193) explains how Hmong-Mien tones developed from an Old Chinese-like segmental opposition of zero, *?, and *h in syllable-final position.

Although there is no way to know for certain if Pyu was as atonal as those other early languages of the region, the odds are currently in favor of little or no tonality in Pyu, at least at an early stage. Whether the script concealed later tonogenesis is still an open question.

\subsection{Response to Shafer's proposal}

Shafer's interpretation of the anusvāra as a glottal stop is no longer possible now that we know Pyu had final stops. $h r a[t] \cdot \dot{m}$ 'eight' $(8.2)^{31}$ could not have been /rat?/ with an impossible final cluster /t?/. One might try to eliminate those clusters by replacing them with a special type of stop, but /rad/ with a final implosive or / rat'/ with a final ejective would be improbable in Southeast Asia. Furthermore, one would have to explain why Pyu developed a special stop in 'eight' absent from cognates with a simple /t/. Alternately, one would have to claim Pyu retained a series of final stops lost in other Sino-Tibetan languages. Lastly, stop interpretations of anusvāra fail to address the correspondences between am and front vowels in related languages or the $a \dot{m} \sim e$ alternation pointing toward $a \dot{m}$ representing a front vowel (§8.1.6.1).

Shafer was not unaware of tonogenesis. A decade before Haudricourt's (1954a, 1954b) landmark papers on tones originating from lost final consonants, Shafer (1943:350) proposed that the modern Burmese falling tone partly ${ }^{32}$ originated from lost prefixes preserved in Pyu: e.g., he thought the first syllable of Pyu pimina /pï ya/ 'five' (3) corresponded to the tone of Written Burmese cl: <nāḥ> [yay] 'five'. His view is no longer in alignment with a current understanding of tonogenesis, and it is unclear how

28 There is disagreement over whether tones in stop-final syllables should be conflated with tones in sonorant-final syllables. Such disagreement has no parallel in Pyu studies, as no one has ever proposed that Pyu had tones in stop-final syllables that were distinct from those of sonorant-final syllables.

29 The figure of fifteen is for Kam which has six tones in stop-final syllables (Yang and Edmondson 2008:514). Those six may or may not be conflated with six of the nine tones in sonorant-final syllables.

$30 \quad$ Liao (2016:51-59) discusses hypotheses of Kra-Dai tonogenesis in depth.

$31 \quad$ The unclear $[t]$ in 8.2 is indirectly supported by cognates with final dental stops such as Old Chinese 八 * $\mathrm{p}^{\text {` }}$ ret 'eight', Old Tibetan brgyad 'id.', and Old Burmese het. 'id.. The contexts of hrat.m in 20.1 and 159 are not sufficiently understood to confirm that it is 'eight' rather than a homophone.

Shafer did not overtly specify "partly", but that is implied from his list on p. 349 of Pyu words without prefixes corresponding to Burmese words now pronounced with a falling tone. He would not have made such a list if he had thought prefixes were the sole source of the Burmese falling tone. 
prefixes would condition the source of that tone which was sometimes written in Old Burmese as $h$. and later as visarga.

\subsection{Response to Luce's proposal}

Even if Pyu was fully tonal, Luce's assumption of iconicity - i.e., that the positions of dots correlated with pitch heights - was hazardous. In the traditional notation for Vedic Sanskrit, a superscript vertical stroke indicates the falling svarita tone, ${ }^{33}$ whereas Luce proposed that a superscript dot (i.e., anusvarra) may indicate a high level tone. In early han'gŭl for Middle Korean, a visarga-like pair of dots indicates a rising tone, ${ }^{34}$ whereas Luce proposed that the Pyu visarga may indicate a falling tone. Luce proposed that the absence of dots in Pyu may indicates a default mid tone, but in traditional Vedic Sanskrit notation, the unmarked default tone was udātta 'raised' (i.e., high), and in early han'gŭl for Middle Korean, the unmarked default tone was low. Modern values for the Chinese 平聲 pingshēng 'level tone' and Kra-Dai and Hmong-Mien A tones - arguably the 'default' tones of those languages - vary considerably in height and contour.

Moreover, Pyu tonal values could have changed so much over time that even if Luce's tonal values were accurate at the time of the creation of the script, they may not have resembled the tonal values of Late Pyu.

Finally, large tone systems in the region result from tone splits following the loss of initial distinctions. Such tone splits are unknown before the late first millenium CE after Pyu was first written. It is highly unlikely that Pyu was the first language in the area to experience a tone split. Its large initial inventory (Table 4) is not characteristic of a language following a tone split. Such a language would have many tones to compensate for a small inventory of initials.

It is true that tonal splits may also be conditioned by vowel length in stopped syllables as in Cantonese, Tai, and Kam. The absence of phonemic vowel length in Pyu may make one wonder if Pyu tones developed to compensate for the loss of long vowels. Could the infrequent combinations of final subscript stops and visarga (\$9.2.2.3) indicate that stopped syllables with proto-long vowels ${ }^{35}$ developed the same tones as sonorant-final syllables with visarga?

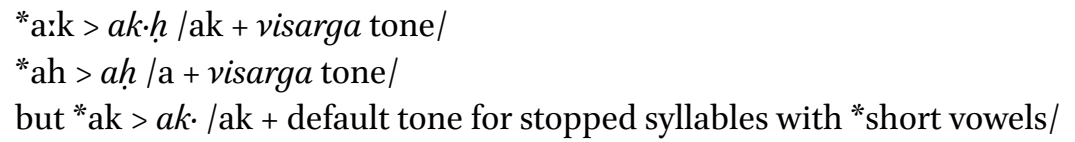

But I suspect that tone splits conditioned by vowel length are even more recent than those condditioned by initials. There is no evidence for vowel length tone splits in the first millennium CE.

In the improbable scenario above, I avoided specifying specific pitch heights and contours. I could have used Tai-like terminology such as DS (the tone of a stopped syllable with a short vowel) and DL (the tone of a stopped syllable with a long vowel). ${ }^{36}$ If Pyu had tones, it would be safest to use such abstract terms instead of committing to specific hypothetical values.

\footnotetext{
33 See Whitney (1896:30) for a description of Vedic tone notation.

34 See Martin (1992:60) for a description of Middle Korean tone notation.

35 I assume here that long vowels were marked and less frequent than short vowels, but the opposite could have been true as in Old Khmer (Pinnow 1979:111).

36 In Tai linguistics, tones are assigned the letters A, B, C, and D. S and L after D stand for 'short' and 'long'.
} 


\subsection{Response to Diller's proposal}

Diller's arguments against tones in Pyu remain valid more than two decades later with one caveat: the Pyu script certainly did indicate codas but not with dots.

Diller foresaw Beckwith's (2002) proposal for what I write as /ä/ (§8.1.6.1) and my proposal for /ï/ (§8.1.6.2) when he wrote that dots could indicate "modifications of vowel quality or quantity, perhaps in tandem with on-line signs."

\subsection{Response to Katō's proposal}

Katō did not explictly state the reasoning for his interpretations of the subscript dot and anusvāra. He may have been motivated by implosives, nasals, and final glottal stops in his proposed glossless Karenic cognates: e.g.,

- dạ̣h * da: 'attributive' (7.1): West Pwo dà '?'

- dim *dĩ 'near' (7.17): West Pwo thêin '?'

- hram *hra? 'eight' (7.2): West Pwo xo? '?'

I have five reasons to reject his interpretation of the subscript dot.

First, it is not possible to judge his Pyu-Karenic comparisons without glosses that he does not provide for his Karenic comparanda.

Second, he did not explain how he came up with Pyu glosses differing from those of Blagden (1919): e.g., his 'near' corresponds to what Blagden regarded as the second syllable of a three-syllable phrase possibly meaning 'in the presence of'. I suspect his reinterpretations of Pyu words are closer to the unstated meanings of his Karenic comparanda.

Third, his cognate sets have unexplained irregular correspondences: e.g., his reconstructed Pyu *d corresponds to West Pwo $t$ and $t h$ as well as $d$.

Fourth, he provided no Karenic parallels for his typologically improbable ${ }^{*} f$, a sound not in any Southeast Asian language to the best of my knowledge, ${ }^{37}$ or his *?j. I presume those reconstructions are by analogy with his reconstructions for other consonants written with subscript dots.

Fifth, $g$ and $v$ with subscript dots are more common than I would expect * 9 or *? w to be. $50.0 \%$ of $g$ in the corpus (146/292) and $54.1 \%$ of initial $v$ in the corpus (113/209) were written with a subscript dot (Table 13). It is unlikely that a glottalized *? w was more common than a plain ${ }^{*} \mathrm{w}$.

See §8.1.6 and §10.2 for my arguments against nasal and glottal stop interpretations of anusvāra.

All previous comparisons of Pyu with other languages need to be reevaluated in light of the current interpretations of the dots and final subscript characters.

\subsection{Response to Krech's proposal}

Krech interpreted consonant-subscript dot sequences as consonants absent from Pali even though those very sequences were in Indic borrowings in the Late Pyu of the Kubyaukgyi inscription, the only inscription Krech examined in his publication. That raises the question of how those borrowings acquired non-Indic consonants. Were Indic words originally borrowed with, for instance, * $\mathrm{g}$, which later shifted to Krech's $g^{\prime}(=g-m$ in this paper's notation)? Subscript dots are in Indic loans throughout the corpus,

37 The phonetically and geographically closest consonant I know of is / $\mathrm{Rg} /$ in the Sandong Miaocao variety of Sui (Wei and Edmondson 2008:586). Unlike Pyu $g-m$, Sandong Miaocao Sui / $\mathrm{gg} /$ is apparently marginal, as Wei and Edmondson place it in parentheses and provide no examples of it. 
suggesting that shift must have occurred early. If * $\mathrm{g}$ became $g$ ', then where $\operatorname{did} g$ - which outnumbers $g$ ' (Table 13) - come from? The high frequency of $g$ also poses a serious problem for the following interpretation of the subscript $\operatorname{dot}(\$ 10.7)$.

\subsection{Response to Miyake's (2017) proposal}

Miyake thought that the subscript dot may have signified breathy phonation because it never occurs with the implosive $b$ / 6 / with only one exception (bam '?' 151) that might be an error for bam '?' (98) with an anusvarra. Phonemic breathy phonation developed in Mon and Khmer to compensate for the loss of *voicing in nonimplosive initials sometime in the second millennium CE. Devoicing was commonplace throughout China and continental Southeast Asia, triggering not only registrogenesis but also tone splits during that period.

However, Pyu had always been written with subscript dots during a much earlier period: i.e., the first millennium CE. Did Pyu undergo registrogenesis long before its neighbor Mon? A simple a priori objection to the phonation hypothesis is that it anachronistically projects a later areal trait onto an earlier language. That objection is not sufficient because Pyu could have been an outlier that was ahead of its time.

There is a stronger typological argument against register in Pyu. If Pyu were like modern Mon and premodern Khmer, it should have had subscript dots with all voiced initials other than its sole implosive /6/. But that is not in fact the case (Table 12). The subscript dot only appears once with $j$ (jam '?' $167^{38}$ ), once with $y$ in a non-Indic akșara (kyaṃh '?' 17.5; §10.8.1.2), once with dl (dlin.ṃm '?'), twice with nasals (tnimmin'?' (20.3; and tmay.ṃh '?' 25.6), and five times with $d r$. It never accompanies $b$ or the liquids $r$ or $l$. It is only strongly associated with three voiced initials: the stops $g$ and $d$ and the glide $v$. In short, the correlation between the subscript dot and voiced initials is weak.

Worse yet, the subscript dot even occurs with voiceless initials. Although rare cases like the sole instance of $k-m$ (20.3) could be written off as errors, $h y-m$ occurs ten times and $h v-m$ occurs nine times. phvum 'day' (5) and hvum 'motion verb marker' (16.3d), the only $h C-m$ morphemes with known meanings, are consistently spelled with a subscript dot. hy and $h v$ without subscript dots respectively occur only four and two times. The subscript dot is far more common after voiceless hy $/ \mathrm{j} /$ than after voiced $y / \mathrm{j} /:$ hy- $m$ outnumbers $y$ - $m$ by a ratio of ten to one in non-Indic words.

TABLE 12 Distribution of the subscript dot in Pyu and breathy phonation in Mon and Khmer

\begin{tabular}{llll}
\hline (Earlier $\left.{ }^{39}\right)$ voiced initial type & Pyu & Mon & Khmer \\
\hline Implosive & $\times$ & $\times$ & $\times$ \\
Pulmonic stop & $\checkmark$ except for $b$ & $\checkmark$ & $\checkmark$ \\
Nasal & only twice & $\checkmark$ & $\checkmark$ \\
Glides $(y v)$ & $\checkmark$ & $\checkmark$ & $\checkmark$ \\
Liquids $(r l)$ & $\times$ & $\checkmark$ & no such initials in Mon or Khmer \\
Liquids $(d r / \mathrm{R} / d l / \mathrm{L} /)$ & $\checkmark$ & \multicolumn{2}{c}{} \\
\hline
\end{tabular}

$38 \quad 167$ is not in Griffiths et al. (2017a). Miles (2016) contains photographs of 167.

39 *Voiced pulmonic (i.e., nonimplosive) stops devoiced in Mon and Khmer following the development of breathy phonation.

40 The $d r$ and $d l$ of Old Mon and Old Khmer are clusters, not unit phonemes like Pyu /R L/. 
TABLE 13 Frequency of subscript dot with $g d v$ in non-Indic akșaras

\begin{tabular}{llll}
\hline & $g$ & $D$ & $v$ \\
\hline With subscript dot & $146(50.0 \%)$ & $341(51.9 \%)$ & $113(54.1 \%)$ \\
Without subscript dot & $146(50.0 \%)$ & $316(49.1 \%)$ & $96(45.9 \%)$ \\
Total & $292(100.0 \%)$ & $657(100.0 \%)$ & $209(100.0 \%)$ \\
\hline
\end{tabular}

And worst of all, the subscript dot often does not occur with the initials that are the most strongly associated with it: $g, d$, and $v$. If breathy phonation regularly developed after those initials, why was it so frequently absent (Table 13)?

There are at least two possible explanations for those anomalies. Both are fatally flawed.

First, one could posit preinitials to account for unexpected voiceless initials and for unexpected clear phonation. The voiceless initial $/ \mathrm{M} /$ in phvum / p.мụ/ 'day' could have developed from a voiceless preinitial-* w sequence after ${ }^{*} \mathrm{w}$ had conditioned breathy phonation: e.g., *pV.sV.wu > *pV.sV.wụ > ${ }^{*}$ pswụ > *ph ${ }^{\mathrm{h}} \mathrm{w}$ > > phvum /p.uụ/. The clear phonation of $g a / g a /$ 'if' (7.25) could have been conditioned by a voiceless preinitial *C that was later lost. An enormous number of preinitials in pre-Pyu would be needed to condition the many exceptions. Syllables with / $\mathrm{j}$ / lacking preinitials are all exceptions. There are no Pyu word-initial syllables of the type $y V(C \cdot) m(h) / \mathrm{j} \bigvee(\mathrm{C}) /$ which should have developed from pre-Pyu *jV(C); all Pyu syllables with a bare initial $y / j$ / would have clear phonation which should have developed from pre-Pyu * C.j. It is unlikely that pre-Pyu had many instances of *C.j but not a single instance of a simple initial $* \mathrm{j}$ that would have conditioned breathy phonation.

Second, one could claim that words with unexpected voiceless initials or clear phonation are borrowings from unidentified substratum languages. Although it would not be unreasonable in theory for Pyu to have borrowed, for instance, $g a$ /ga/ 'if' from a language that lacked breathy phonation after voiced initials, it would be unreasonable to propose the existence of entire languages whose sole raison d'etre would be to solve an issue in Pyu phonology. Moreover, if, say, phvum /p.mụ/ 'day', had been borrowed from *p.mụ in another language, that language would have had the same anomalies as Pyu: it would have had phonemic breathy phonation as early as the first millennium CE before Mon developed it, and it would have had that phonation in voiceless-initial syllables that were unlikely to develop it. In short, a loanword scenario merely projects issues in Pyu onto a hypothetical language whose questionable existence would be an additional issue.

Neither the preinitial nor borrowing scenarios can credibly account for the near-total absence of the subscript dot with voiced nasals and its total absence with $r$ and $l$. Claiming that almost every single syllable with a voiced nasal or voiced liquid initial either lost a preinitial or was a borrowing multiplies the absurdity of making such claims for every single syllable with a bare initial $y$.

The phonation hypothesis is in line with the current trend of reconstructing few or no tones in early Southeast Asian languages, but otherwise has no merit. It is typologically implausible upon closer examination and has many exceptions whose supposed explanations add further complications.

\subsection{Revisiting Krech's proposal: the fricative hypothesis}

10.8.1 The four $C$ - $m$ in Indic loans in Pyu

I was skeptical about Krech's proposal because of an apparent paradox: if the subscript dot indicated non-Pali consonants, why did those consonants appear in Pali loans in Pyu? But it becomes clearer that there was never any paradox if one rewords the question: Why did the Pyu pronounce Pali with non-Pali consonants? 
The key to the answer lies in the distribution of those consonants. They never appear in initial position in Indic loans with one exception (\$10.8.1.1). All other apparent instances of dotted consonants in initial position can be explained away as members of compounds:

- gomdama 'Gautama' after ḅuddha (24 IV)

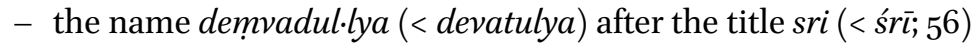

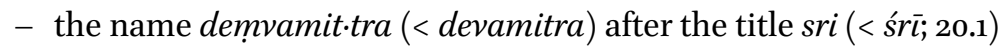

- demvvim (< devī) 'queen' after the name tridogavamiasaga (< trilokāvatamisaka; 7.4)

- demvvim (< devī) 'queen' after the name tridogavadasaga (< trilokāvataímsaka; 8.3)

- vimmmkhno 'Vishnu' after baṃh 'honorific' (17.2)

All instances of $\mathcal{C}$ - $m$ in Indic loans are intervocalic with only two definite exceptions which both contain glides:

- kasyamba (< kāśyapa; 24 III)

- sagaṃsirvaṃrabadimmim (< saṁghasenavarapaṇdita; 8.17)

sy-m may be a special spelling for the non-Pyu palatal fricative $s[6]$ (§10.8.1.2).

The only other definite instance of $C$ - $m$ after consonants in a polysyllabic loan is in the name samanardomminh (8.20) of unknown origin ${ }^{41}$ corresponding to Old Burmese sak.munalon. (7.30) and Old Mon sak.munalor. (7.25). Perhaps $r d \underline{-}-\underline{m}$ is to be taken as a single unit representing a nonPyu, non-Old Burmese, non-Mon consonant that sounded like /l/ to Old Burmese and Old Mon speakers.

There are potential instances of $\mathcal{C}-\underline{m}$ after nasals if one assumes that nasal codas were still present but not written in the Kubyaukgyi inscription: e.g., an unwritten $\dot{n} \cdot / \mathrm{y} /$ in sagam- 'monastic community'

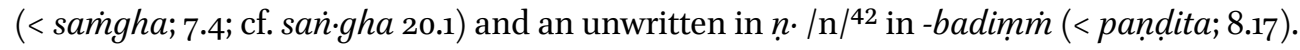

$C-m$ in Indic loans is always between sonorants. The first sonorant is almost always a vowel, and the second sonorant is always a vowel. Consonants are likely to lenite between sonorants. If $C$ - $m$ occurred after nasals, it could represent stops that had lenited after nasals.

The places of articulation of the four $C-m$ in Indic loans match the four places of articulation of Pyu stops other than the Late Pyu retroflex phonemes / $\mathrm{D} /$ and perhaps $/ \%$ if it was a glottal stop / $/$ (Table 14). No lenited versions of / $\mathrm{d}$ D $\mathrm{P} /$ would be expected since /d/ patterns like a liquid rather than a stop, /D/ may have been the voiceless counterpart of /d/, and / $/$ / would probably lenite to zero.

$41 \quad$ Luce (1985:39) identified this village as Sak, presumably because its Mon and Old Burmese names contain the syllable sak. and because there was a village "below Pagán" called munalvan. in Old Burmese (Luce 1985:45). But even if Sak speakers lived in that village, there is no guarantee that the Pyu, Mon, and Old Burmese names are based on a Sak name rather than an exonym. Hence I am hesitant to regard the source of those names as Sak. It is also not certain whether Old Burmese sak.munalon. and munalvan. refer to the same village; it is conceivable that the former was 'the Munalon of the Sak' while the latter was a different village belonging to speakers of some unknown language.

42 Although the Pyu script had Indic retroflex characters, Pyu had no retroflex nasal (Table 4). 
TABLE $14 \quad C$ - $m$ in Indic loans compared with Pyu stops

\begin{tabular}{lllll}
\hline $\begin{array}{l}\text { Stop type } \backslash \\
\text { Place of articulation }\end{array}$ & velar & Palatal & dental & Labial \\
\hline$?$ & $g-\underline{m}$ & $y-\underline{m}$ & $d-\underline{m}$ & $v-\underline{m}$ \\
Voiceless unaspirated & $/ \mathrm{k} /$ & $/ \mathrm{c} /$ & $/ \mathrm{t} /$ & $/ \mathrm{p} /$ \\
Voiceless aspirated & $/ \mathrm{k}^{\mathrm{h}} /$ & $/ \mathrm{c}^{\mathrm{h}} /$ & $/ \mathrm{t}^{\mathrm{h}} /$ & $/ \mathrm{p}^{\mathrm{h}} /$ \\
Voiced & $/ \mathrm{g} /$ & $/ \mathrm{f} /$ & $/ \mathrm{d} /$ & $/ \mathrm{b} /$ \\
\hline
\end{tabular}

TABLE $15 \quad C$ - $m$ in Indic loans compared with voiced lenited stops in other languages

\begin{tabular}{lllll}
\hline Pyu Indic loans & $g-\underline{m}$ & $y-\underline{m}$ & $d-\underline{m}$ & $v-\underline{m}$ \\
\hline Middle Vietnamese (Gregerson $\left.1969^{43}\right)$ & $g(h) / \gamma /$ & $g i / \mathrm{dz} /$ & $d / \mathrm{d} /$ & $\mid b / \beta /$ \\
Middle Korean & $/ \gamma /$ & $/ \mathrm{z} /$ & $/ \mathrm{r} /$ & $/ \beta /$ \\
Tangut (Miyake 2012) & $/ \gamma /$ & $/ \mathrm{z} /$ & $/ \mathrm{l} /$ & $/ \mathrm{v} /$ \\
Old Irish & $/ \mathrm{\gamma} /$ & - & $/ \mathrm{\gamma} /$ & $/ \mathrm{v} /$ \\
\hline
\end{tabular}

That alignment is expected if the four $C$ - $m$ originated as lenited stops. Other languages also have voiced lenited stop series that align well with the four $C$ - $m$ of Pyu (Table 15).

I propose that the four $C$ - $m$ in Indic loans were fricatives absent in standard Sanskrit and Pali pronunciation: / $\Varangle j \partial \beta /$. Those fricatives were in Pyu pronunciations of Indic loans either because Pyu had a rule of intervocalic lenition or because they reflected nonstandard Sanskrit and Pali pronunciation. All four fricatives are in line with what is known about lenition of stops and fortition of glides in Middle Indic, as I will explain in §10.8.1.1-§10.8.1.4.

I assume that the four $C$ - $m$ in Indic loans were pronounced identically in native Pyu words, though there is no guarantee that a character would have the same pronunciation in different vocabulary strata: cf. how German $v$ is [f] in native words but [v] in borrowings. The four $C$ - $m$ occur both after preinitials and in bare initial position in native Pyu words.

In words like tdum /t.ðu/ 'water' (7.18), the preinitial /t./ was probably a presyllable like [tə] whose vowel was the first half of the conditioning environment for the lenition of a following dental stop *T. A reviewer suggests that the /t./ of 'water' may be cognate to the rGyalrong indefinite possessive prefixes $t u$ - and $t \gamma$ - that have "become frozen and reanalyzed as part of the root" (Jacques 2018:18-19): e.g., Japhug tu-ci 'water'.

Not all preinitials conditioned lenition, as there are words with preinitials followed by stops: e.g., $k c a$ 'disease' (16.4C) instead of the expected †kyam from *k.ca. Perhaps words like 'disease' were disyllables like *kVca when lenition only affected sesquisyllables like *t.Tu 'water'.

In $t d a v \cdot m h$ /t.ðam/ 'king' (12.1), the preinitial /t./ appears to be the conditioning factor for lenition as in 'water', but in reality is a reduction of an earlier full syllable tar. still present in tar. dav.ṃh /tar ðam/ 'king' (12.1). The /ð/ of the second syllable may be from a dental stop that lenited after $/ \mathrm{r} /$ in close juncture. That stop may be *d if the second syllable of 'king' is derived from dav.h /dam/ '?' (12.3).

43 I have substituted Gregerson's phonetic symbols for his Vietnamese orthography-based phonemic notation. I have retained his non-IPA symbol dž since I am not certain whether it is equivalent to $/ \mathrm{d} z /$ or $/ \mathrm{d} z /$. My guess is that it was palatal $/ \mathrm{d} z /$ since it originated from lenited intervocalic palatal stops. 
In some cases, a preceding presyllable or syllable that conditioned lenition may have been lost, resulting in a bare initial fricative: e.g., dammm /ðä/ (7.9) may be an abbreviation of the past marker ta damm / ta ðä/ (7.5; Blagden 1919:65). Similarly, dav·ṃh /ðам/ '?' (27.1) may be an even shorter form of tar.dav·ṃh /tar ðам/ tdav.ṃh /t.ðaм/ 'king'.

$d u k \cdot m$ / ðuk/ 'time' (16.1C) is in structures of the type 'X time' and may be from an earlier *duk (perhaps the same word as $d u k \cdot$ '?' 20.5) whose *d lenited in close juncture with preceding words. The fricative initials of postnominal and postverbal markers such as dan்m /ðay/ 'instrumental and comitative marker' (16.4A), dum /ðu/ 'in' (7·7), and vaì.ṃ /vay/ 'plural marker for nouns, pronouns, and verbs' (16.3C) may be from earlier stops that lenited after final sonorants in close juncture.

In other cases, bare initial fricatives may not be reflexes of stops that lenited after a lost presyllable or syllable: e.g., if vam /va/ 'to go' (16.1A) is cognate to Old Chinese 于 * ${ }^{\mathrm{w}}$ (r)a 'id., /v/ might be the Pyu reflex of a Proto-Sino-Tibetan * $\mathrm{G}^{\mathrm{w}}(\mathrm{r})$. Similarly, if gam / $\mathrm{\gamma a} /$ 'to plunge into' (16.3A) is cognate to Old Chinese 下 * ${ }^{\text {S }}$ ra? 'down', / $/$ / might be the Pyu reflex of a Proto-Sino-Tibetan * $\mathrm{g}^{\mathrm{s}} \mathrm{r}$.

Still other words with bare initial fricatives could have been borrowed, though this is speculative since no foreign sources for such words have been identified. Old Burmese and Old Mon cannot be sources since they lacked the fricatives $/ \gamma j \precsim \beta /$, but perhaps there were other languages in the region that had such consonants. e.g., Proto-Karen which may have had ${ }^{*} \gamma \cdot{ }^{44}$

In many cases, there is no evidence pointing toward any explanation for bare initial fricatives: e.g., dimm /ði/ 'to say/pray' (7.22) has no known longer variants or cognates.

10.8.1.1 $g-m / \gamma /$

Pali retains original medial voiced stops, but in later Middle Indic languages that Masica (1991:180) calls Middle Prakrit or Second Stage Middle Indo-Aryan, such stops lenited to fricatives in intervocalic position: e.g., $g$ became $\gamma$. Hence Pyu $g-m$ / $/ \gamma /$ in dathagam as pronounced with a Middle Prakrit accent. But it is also possible that Pyu speakers applied their own native rule of lenition to a foreign intervocalic $g$.

gom / үo/ 'cave-pagoda' (also spelled gaum in 16.2A), a borrowing from Sanskrit or Pali guhā 'cave', is attested four times after deictics $(7.20,7.22,8.20,8.22)$, twice as the object of a verb (7.19, 8.19), and once after the honorific bay.ṃh (16.2A). Perhaps 'cave-pagoda' was phonemically /go/ with an initial /g/ that weakened to $[\mathrm{y}]$ after a sonorant in close juncture. go '?' $(20.3,29,37,39,66,93)$ may be the same word in phrase-initial position or a phonemic spelling in close juncture.

10.8.1.2 $y-m / j /$

$y$ - $m$ is the most poorly attested of the $C$ - $m$ consonants in Pyu, so its interpretation is the most speculative.

In post-Pali Middle Indic, $j[\mathrm{dz}]$ intervocalically lenited to [3] (Masica 1991:180). Indic scripts are not IPA and generally lacked characters for voiced fricatives other than $h / h /, 45$ so the phonetic values of

44 Jones (1961:100), Burling (1969:37), Haudricourt (1972:134), and Katō (2018:32) reconstruct Proto-Karen * ${ }^{*}$, but Manson (2009:20) and Luangthongkum (2014:4) do not.

$45<\mathrm{h}>$ in Indic scripts for Indo-Aryan languages represents voiced [ $\mathrm{h}$ ], not voiceless [h]. The Indic script symbols transliterated as $\langle\mathrm{v}\rangle$ originally represented a glide $/ \mathrm{v} /$, not a fricative /v/. Kharoșthī has special modified characters and a $<\mathrm{z}\rangle$ borrowed from Aramaic to represent voiced fricatives absent from Sanskrit (Glass 200o). 
lenited forms are reconstructed almost entirely on the basis of alternations between "vacillation in writing a voiced stop, semivowel, or nothing" (Masica 1991:181). I suspect that $j$ could have lenited to alveopalatal $[z]$ or palatal $[j]$ as well as palato-alveolar [3]; scripts alone cannot point to any of these specific values.

I would predict that intervocalic $j$ would appear as $y$ - $m$ in Indic loans in Pyu, but this is never the case: e.g., rājakumāra appears as rajaguma (7.4), not †rayamguma. Pyu also lacks j-ṃ in Indic loans. However, $y$ - $m$ does exist in two Indic loans in Pyu:

- ${ }^{\circ}$ arimedeyam (< ariyamettayya 'noble Maitreya' 7.26)

- kasyamba (< kaśyapa; 24 III)

Medial $-y y$ - could harden to $-j j$ - in post-Pali Middle Indic (Masica 1991:169). This orthographic -jj- might have represented a geminated fricative [zz] $\sim$ [jij partway between a glide $y[j]$ and a palatal affricate $j$ [dz]. If Pyu speakers heard Pali mettayya 'Maitreya' pronounced with a Middle Prakrit accent as [mettazza] or [mettajja], they could have approximated it as -medeyam /medeja/ with $y$ - $m$ / $/ \mathrm{j} /$. I reconstruct $/ \mathrm{j} /$ rather than a $/ \mathrm{z} /$-like fricative because the spelling $y-m$ implies that the consonant it represented sounded more like $y / \mathrm{j} /$ than $j / \mathrm{f} /$.

The $y$ - $m$ in kasyamba is more difficult to explain. sy-m may be a unique attempt to write Sanskrit $s$ [ 6 ] without using the rare character $s$ that only appears in two texts (24 and 27). [6] is voiceless like $s$ and palatal like $y-m$ [j]. kasyamba and śri (24 bottom; $2 \times)$ are on different parts of a silver reliquary and may be by two different hands using two different spellings for the same sound.

$y$ - $m$ is only in a single non-Indic akșara from Halin, kyaṃh /k.jah/ '?' (17.5).

$j$ - $m$, possibly a spelling of a more $j$-like allophone $[\mathrm{z}] \sim[\mathrm{z}] \sim[\mathrm{z}] \sim[\mathrm{z}]$ of $y$ - $m$, is also only in a single non-Indic akșara on a censer fragment from Sriksetra, jam /ja/ '?' (167). jam follows mau /mo/, whose vowel might have conditioned the lenition of a palatal initial */C/ in the following syllable: */mo Ca/ > / mo ja/. There are no other instances of akșara sequences of the type †mau $\mathrm{Ca}$, so I do not know if mau jam is two words, a compound, or a disyllabic root word.

Perhaps kyaṃ̣ and jam represent archaisms remaining after all other lenited palatals had merged with $/ \mathrm{j} /$. They could reflect a dialect retaining / $/$ /; their cognates in standard Pyu might have been kyah /k.jah/ 'to cause' (7.10) and ya /ja/ '?' (20.2). It would be easy for speakers to merge a lenited palatal /j/ with a very similar-sounding /j/. In Saigon Vietnamese, the lenited palatal /dž/ became /j/.

10.8.1.3 d- $\quad$ - $m / \partial /$

In post-Pali Middle Indic, $d$ intervocalically lenited to [ð] (Masica 1991:18o). Hence Pyu $d-m$ /ð/ in -adimmintya (< a ditya; 7.3) may reflect Sanskrit $d$ as pronounced with a Middle Prakrit accent. But it is also possible that Pyu speakers applied their own native rule of lenition to a foreign intervocalic $d$.

There is one Indic loan in Pyu with $d$-m $m$ seemingly corresponding to $t$ : radamna /raðana/ 'jewel' (20.1) whose Pali equivalent is ratana. However, I suspect the word is from a Prakrit *radana with medial * $\mathrm{d}$ similar to the attested form ladana (Turner 1962-66:613). The fricative in /raðana/ would then be the result of Pyu-internal lenition.

10.8.1.4 v-m $v / \beta /$

In post-Pali Middle Indic, $b$ intervocalically lenited to $[\beta]$ (Masica 1991:180). Hence one might expect to find Pyu $v-m / \mathrm{v} /$ corresponding to Indic $b$. But in fact there are no such cases unless Pyu vimimkhno 
'Vishnu' (17.2) is based on a Middle Indic pronunciation of viṣnu as something like †bikhṇu. ${ }^{46}$ This does not necessarily mean that the Pyu never encountered a lenited $b$ in the Indic that they heard or that they would never have written such a $b$ as $\nu$ - $m$. It is also not necessarily evidence against a native Pyu rule of intervocalic lenition of $/ \mathrm{b} /$. It may simply reflect the fact that none of the Indic loans in the corpus originally had $b$ in intervocalic position. $b$ in Indic borrowings usually corresponds to Sanskrit or Pali initial $b$ or medial $p$ which lenited to [b] in post-Pali Middle Indic (Masica 1991:180).

In any case, all instances of Pyu $v-m / v /$ correspond to Indic $v$. This may imply that the then-current Indic pronunciation of $v$ was somehow different from Pyu $v / w /$. If that was the case, the Pyu did not feel obligated to consistently write Indic $v$ as $v-m$, as the frequent name element vikrama never appears in Pyu as †vimkrama. Some scribes may have left out the subscript dot because they felt that it was obvious that $v$ had a special pronunciation in Indic words.

I assume that $\nu$ - $m$ was a fricative like other $C-m$, but all that can be said for certain is that $\nu-m$ and $\nu$ were different phonemes. Their precise phonetic values may have varied through space and time: e.g., $\nu-m$ may have been $[\beta], v$ may have been $[v]$, etc. I choose a fricative symbol $/ v /$ for $\nu-m$ to be consistent with other fricative symbols for $C$ - $m$ and to match the usual transliteration of Indic $\nu$. On the other hand, I choose a glide symbol $/ \mathrm{w} /$ for $v$ because that phoneme patterns like the glide $y / \mathrm{j} / ;$ both $/ \mathrm{w} /$ and $/ \mathrm{j} /$ appear in coda as well as initial position, whereas no fricatives other than $/ \mathrm{h} /$ may appear as codas.

If the Indic pronunciation of $v$ were, say, [v], and the Pyu had [w] and [v], why did the Pyu write their $[\mathrm{w}]$ as $v$ ? Perhaps the Pyu realized that $[\mathrm{w}]$ was much more common than $[\mathrm{v}]$ in their language and decided to write the more common consonant without a diacritic. The problem is that $\nu$ - $m$ actually outnumbers $v$ in the corpus by a ratio of 1.18 to 1 (113:96). However, the number of unique akșaras with $v$ does slightly outnumber those with $v$ - $m$ by a ratio of 1.09 to $1(47: 43)$.

The first literate Pyu may have been familiar with at least the rudiments of the Sanskrit phonetic tradition. Maybe they recognized that their $/ \mathrm{v} /$ belonged to a class of voiced fricatives rather than in a class of glides like $/ \mathrm{j}$ / and wrote / $/ \mathrm{w}$ with a subscript dot like the other voiced fricatives even though it may have been more phonetically similar to an Indic $v$. Conversely, their /w/ might not have sounded like an Indic $v$, but it was a glide like Indic $v$ and therefore they wrote it as $v$.

10.8.2 $\quad C-m$ not in Indic loans

It is more difficult to determine the pronunciation of combinations of consonant symbols and subscript dots that do not occur in Indic loans.

10.8.2.1 hy-m

I interpret hy- $m$ as /ç/ which is voiceless like $h y / \mathrm{j} /$ and a palatal fricative like $y$ - $m$ /j/. Both /ç/ and /j/ appear exclusively before /a/. They are not in complementary distribution with any other palatal consonant, so neither can be an allophone of a third phoneme before $/ \mathrm{a} /$.

The phonetic distinction between $/ c ̧ /$ and $/ \mathrm{j} /$ is extremely fine, so it is possible that hy- $m$ represents a fricative allophone of hy $/ \mathrm{j} /$. . However, that cannot be confirmed until all members of these potential minimal pairs are glossed:

46 Pyu $k h$ may reflect confusion between $s ̣$ and $k s ̣ . s ̣ n$ regularly becomes $n h h$ in Middle Prakrit (Masica 1991:178). $n h$ could have been erroneously Sanskritized as kṣn (cf. Prakrit tịnha 'sharp' from Sanskrit tīkṣna) and then semi-Prakritized as khṇ. kkh is one common Prakrit reflex of medial kș (Masica 1991:177).

Written Burmese < bissanuih > [bei? Өə no y] 'Vishnu', the modern name of the Pyu site known in English as Beikthano, may also be based on a * $b$-pronunciation of 'Vishnu'. 
hya '?' (23.3) : hyam '?' (25.4)

hyaḥ 'body' (16.5b) : hyaṃh '?' (32.6)

I could make /ç/ more phonetically distinct from $/ \mathbf{j} /$ by interpreting it as a palatal sibilant $/ 6 /$. I am reluctant to do so because if Pyu had such a sibilant, it would have been written as ś and not as hy-m. Also, the borrowing of Sanskrit śrı as sri (7·3) suggests that Pyu lacked a consonant like Sanskrit ś.

\subsubsection{2 $h \nu-m$}

Unlike $h y$ - $m$ which may be a fricative phoneme distinct from its glide counterpart $y$, I regard $h v$ - $m$ as an allophone [f] of its glide counterpart $h v / \mathrm{M} /$.

I interpret $h v-m$ as [f] which is voiceless like $h v / \mathrm{M} /$ and a labiodental fricative like $v-m, \mathrm{v} /$. If $v-m$ was bilabial [ $\beta$ ], its voiceless counterpart $h \mathcal{v}-m$ would be [ $\phi]$. The use of $h v$ in $h \mathcal{v}-m$ for [f] is similar to the modern Khmer use of บी $<\mathrm{hv}>$ for $/ \mathrm{f} /$.

$h \nu$-ṃ occurs only before /u/ in two akșaras: phvum /p.Mu/ 'day' (5) and hvum / $\mathrm{Mu/} \mathrm{'marker} \mathrm{for} \mathrm{motion}$ verbs' (16.3d). There are no minimal pairs with $h v-m$ and $h v$. $h v$ only occurs before $a$ in two akșaras: $h v a m$. / mam/ '?' (23.5) and phva /p.ma/ '?' (64.5). The complementary distribution of $h v-m$ and $h v$ may be accidental due to the small size of the corpus. The future discovery of minimal pairs would necessitate positing /f/ as a separate phoneme distinct from $/ \mathrm{M} /$.

\subsection{The mystery of $Z$}

Blagden (1911:383) observed that in the Kubyaukgyi inscription, "there are also in several places marks above or between the lines to which I cannot at present attach any definite meaning." Griffiths et al. $(2017 \mathrm{~b})$ established that the interlinear "marks" are in fact the subscript consonants in lines 2 and 3 of inscription 8. However, both pillars of the Kubyaukgyi inscription contain "marks above [...] the lines" which have not yet been identified. Griffiths et al. (2017a) have transliterated these superscript arc strokes as $Z$.

These arcs are the most enigmatic characters in the Pyu script. They have no known parallels in other Indic scripts. They occur 16 times with seven different morphemes in the Kubyaukgyi inscription. At least six out of the seven morphemes are grammatical. All seven also occur elsewhere without $Z$ in the Kubyaukgyi inscription, so $Z$ is not an inherent part of their spelling.

TABLE 16 The distribution of $Z$ in the Kubyaukgyi inscription

\begin{tabular}{|c|c|c|c|}
\hline $\begin{array}{l}\text { Morpheme and adjacent } \\
\text { punctuation }\end{array}$ & Line in 7 & Line in 8 & Gloss (Blagden 1919) \\
\hline cheZ\| & 13 & 13 & particle or verbal auxiliary \\
\hline choh?Z\| & 12 & 12,29 & final particle \\
\hline choh $\| Z$ & $\begin{array}{l}\text { 26; presumably an error } \\
\text { for chohZ\| }\end{array}$ & See 8.29 above & \\
\hline daZ & 3,24 & 3 (8.26 has $d a$ instead of $\dagger d a Z)$ & 'was' in 3 ; 'or' in 24 \\
\hline toḥZ $\|$ & 5,11 & 5,11 & particle after verbs \\
\hline paZ $\|$ & 23 & $\begin{array}{l}\text { (the corresponding section is } \\
\text { damaged) }\end{array}$ & (unknown) \\
\hline $\operatorname{maZ} \|$ & (no $Z$ in 19$)$ & 19 & particle \\
\hline roḥZ\| & $($ no $Z$ in 8$)$ & 8 & particle; perhaps 'when' \\
\hline
\end{tabular}


Shafer (1943:318) noticed that $Z$ was "always found on the last word before the punctuation marks" with the exception of $d a$ (which Shafer read as $l a$ and interpreted as 'and' in 7.3 and 8.3). He was the first to propose its possible functions:

From its position just before the punctuation marks in all cases except where it occurs over la, which is a conjunction, we may conclude that it is either some additional mark of punctuation or that it was not an inherent tone but one induced by the sentence structure, perhaps something like the English falling tone or the French rising tone at the end of a sentence.

Krech (2012:153) similarly wrote that "the positions of its occurrences suggest that this sign represents prosodic or intonational features".

I have no objections to Shafer and Krech's views on $Z$, and can only add that this symbol may be of historical importance as an early example of prosodic notation in an Indic script and a rare example of prosodic notation outside a liturgical context. ${ }^{47}$

\section{Conclusion}

This article only deals with elements of Pyu monosyllables: rhymes and several fricative initials that I discovered when I tackled the question of whether Pyu had tones (§10). I have attempted to provide a synchronic foundation for the further study of Pyu phonology. I hope to build upon that foundation by exploring three topics in the future.

First, I would like to reconstruct Pyu polysyllabic phonology primarily by examining Indic loanwords. I would also include the few known non-Indic polysyllabic words in this survey. I am particularly interested in explaning why Pyu often has voiced consonants corresponding to Indic voiceless consonants: e.g., dathagamda (7.1) for tathägata. In that particular case, the un-Indic $d$ may be the result of intervocalic voicing. The initial $d$ is preceded immediately by siri, and of course the second $d$ is between vowels. However, it is not yet clear whether the lenition of $t$ in intervocalic position - a known phenomenon in Prakrit - reflects Middle Indic pronunciation or a Pyu rule.

Second, I would like to look at Chinese character transcriptions of what may be Pyu words in Chinese historical records. Using a smaller-scale version of Miyake's (2003) methodology for reconstructing Old Japanese phonology on the basis of a much larger body of Chinese character transcriptions, I could see what can be recovered from, for instance, the titles of the twelve 驃 'Piào' songs in 新唐書 (Xìn Táng shū; New History of the Tang). So far only the transcription 沒䭾 for 'Buddha' has received attention in the literature (Luce 1985 I:72, Griffiths et al. 2017b:66), but much more can be done with that material and other transcriptions catalogued though not analyzed by Luce (1985).

Third, I would like to reconstruct pre-Pyu, a stage of the language preceding written records, on the basis of internal evidence in a fashion similar to the reconstruction of pre-Tangut in Miyake (2012). I could then use pre-Pyu in comparisons with other Sino-Tibetan languages to tackle the question of where Pyu belongs in the Sino-Tibetan family.

47 There are special systems of prosodic notation for chanting the Hebrew Bible and the Qur'an. They are not used for writing new texts in Hebrew or Arabic. See Dresher (1994:3) and Sawalha et al. (2012:179-181) for descriptions of these systems. 
While continuing to work on Pyu phonology, I will also be analyzing the three Pyu multilingual texts other than the Kan Wet Khaung Sanskrit-Pyu bilingual statue inscription (16) already examined by Griffiths et al. (2017b): the Old Burmese-Old Mon-Pali-Pyu Kubyaukgyi inscription ( 7 and 8), the SanskritPali-Old Mon-Pyu Myittha stela inscription (39), and the Chinese-Pyu Tharaba Gate inscription (11). Any Pyu words I might be able to identify could strengthen my account of Pyu phonology by making it slightly less asemantic. Discovering the meanings of a mere three syllables could make or break the phonemic status of /ç/ (§10.8.2.1). The ignorance of the meanings of most Pyu words remains the biggest barrier for major progress in this subfield of Pyu linguistics.

\section{Appendix 1: A lay transcription of Pyu}

As Burma opens up to the world and promotes the remains of the Pyu cities of Sriksetra, Halin, and Beikthano as UN World Heritage sites, the need for a standardized transcription of Pyu for nonscholarly publications becomes increasingly urgent. Such a transcription should ideally reflect the phonology of Pyu while also being easy to type and difficult to distort or misinterpret.

Simply recycling the transliteration system used in this paper does not fulfill those criteria. dal.mmma / ðäl/ (16.6A) would probably end up without a middle dot or diacritics as dalmmh in a newspaper article and be pronounced as if it rhymed with calm. The transliteration system is intended to reflect the elements of the script in a manner that is easy for people acquainted with Indological tradition to understand. It is neither phonemic nor intended for lay usage. It can, however, serve as the basis for a lay transcription if the following rules are applied.

\section{Consonants}

1. Delete the vowel-initial symbol ${ }^{\circ}$.

2. Convert $\dot{n}$ to $n g$.

3. Convert $c$ and $c h$ to $c h$ and $c h$. Alternately, both $c$ and $c h$ could be converted to $c h$ to avoid the unusual trigraph $c h h$. In either case, $c$ should be avoided, as it may be misread as [k] or [s].

4. Delete all subscript dots from letters for retroflex consonants, $b$, and $h$. Most readers will not be familiar with retroflex consonants, implosives, or visargas.

5. Convert $v$ to $w$.

6. Convert $g-m$ to $g h$, the digraph for Arabic $/ \gamma /$.

7. Convert $d-m$ to th, the digraph for English and Burmese /ð/.

8. Convert $h v-m$ to $f$. The transcription is phonetic, and readers unfamiliar with Pyu allophony would not benefit from a phonemic transcription of phvum 'day' (5) as phwu instead of a phonetic transcription $p f u$.

9. $\quad$ Delete all other $m$.

The distinction between $y / \mathrm{j} /$ and the rare consonant $y-m / \mathrm{j} /$ is too fine to merit preservation, as is the distinction between hy /j/ and hy-m /ç/.

Simplifying $v-m$ results in $\nu$ which is either identical to $/ \mathrm{v} /$ or close to $/ \beta /$.

Other $C-m$ combinations are rare and their interpretation is uncertain, so it is best to simply omit the $m$. 
10. Delete the middle dot after subscript consonants.

11. If a text lacks subscript consonants, restore final consonants in words known to have them in texts with subscript consonants. Enclose these restored consonants in parentheses.

12. Capitalize proper nouns when they can be identified.

\section{Vowels}

1. Convert the anusvāra to a diaeresis on the preceding vowel: e.g., am to $\ddot{a}$.

2. Convert $a u$ to $o$. The $a u$ : $o$ distinction is purely graphic and has no phonemic significance (\$8.1.5).

3. Convert $r$ to $r i$ or $\ddot{\text { ir }}$ if its phonemic value can be determined (§8.2.2). Otherwise convert it to $r i$, as an open syllable is more likely than a closed syllable.

4. Delete macrons.

The transcription resulting from these rules is not ideal. It is not reversible: it cannot be unambiguously converted back into transliteration. It is solely meant for laypeople to have some idea of how Pyu words were pronounced. It is not language-neutral: it assumes an acquaintance with English orthographic conventions which are widely known. Nonetheless it remains preferable to the existing transliteration for the citation of Pyu forms in the lay press.

\section{Appendix 2: Sample Pyu texts in transliteration, phonemic transcription, and lay transcription}

These transliterations are from Griffiths et al. (2017a) without punctuation. The transcriptions are mine. I treat uncertain readings as if they were certain in the transcriptions for simplicity.

Inscription 1 is on a small stela found in Halin. It is now in the Halin museum. It is a two-line example of Pyu script with final subscript consonants such as $y \cdot$ in $b a y \cdot \dot{m} h$.

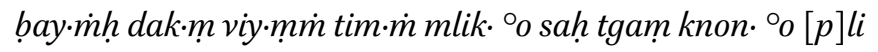

/ bäj đak vïj tïm m.lik ${ }^{\circ}$ o sah t.ya k.non ${ }^{\circ}$ o p.li/

bäyh thak vïy tïm mlik o sah tgha knon o pli

bay.min lun. ba hi ${ }^{\circ}$ o lup $\cdot y a \dot{m}$

/ bäj luy ba hi ${ }^{\circ}$ o lup jä/

bäyh lung ba hi o lup yä

Inscription 3 is a single long line on one of a set of five stone urns found in Sriksetra. Those urns are now in the Sriksetra museum. I chose inscription 3 as a short example of Pyu script without final subscript consonants. In its transcriptions, I have restored the final consonants of tdaṃh 'king', bam orific', snih 'year', and hau 'three' on the basis of other texts where they are written with final subscript consonants. Other words in this inscription may also have had final consonants that I am unable to restore.

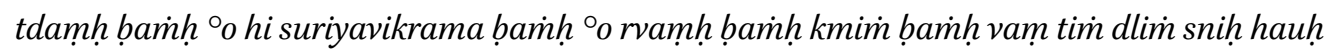

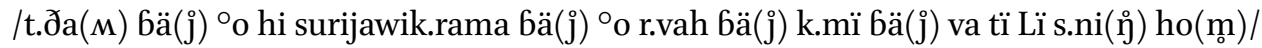
ttha $(w) h$ bä $(y) h$ o hi Suriyawikrama bä $(y) h$ o rvah bä $(y) h$ kmï bä $(y) h$ va tï dlï sni $(n g) h$ ho $(m) h$ 
su pim ṅa ta kim kha ${ }^{\circ}$ o sniḥ ḅamh ${ }^{\circ}$ o ru kleh yam

/su pï ya ta kï $\mathrm{k}^{\mathrm{h}}{ }^{\circ}{ }^{\circ}$ s.ni(号) 6ä(j) ${ }^{\circ}$ o ru k.leh jä/

su pïnga ta kï kha o sni(ng)h bä $(y)$ h o ru kleh yä

\section{References}

Baxter, William H., and Laurent Sagart. 2014a. Old Chinese: A New Reconstruction. Oxford: Oxford University Press.

Baxter, William H., and Laurent Sagart. 2014b. Baxter-Sagart Old Chinese reconstruction, version 1.1. http: //ocbaxtersagart.lsait.lsa.umich.edu/BaxterSagartOCbyMandarinMC2014-09-20.pdf. Accessed 30 September 2014.

Beckwith, Christopher I. 2002. A glossary of Pyu. Medieval Tibeto-Burman Languages: Proceedings of the gth Seminar of the International Association of Tibetan Studies, Leiden 20oo, ed. by Christopher I. Beckwith, 159-161. Brill's Tibetan Studies Library, 2/6. Leiden: Brill.

Blagden, C.O. 1911. A preliminary study of the fourth text of the Myazedi inscriptions. Journal of the Royal Asiatic Society of Great Britain and Ireland 1911: $3^{65-388 .}$

Blagden, C.O. 1919. The Pyu face of the Myazedi inscription at Pagan. Epigraphia Birmanica 1: 59-68.

Bucknell, Roderick S. 1994. Sanskrit Manual. Delhi: Motilal Banarsidass.

Burling, Robbins. 1969. Proto-Karen: a reanalysis. Occasional Papers of the Wolfenden Society on Tibeto-Burman Linguistics 1: 1-116.

De Bray, R.G.A. 1980. Guide to the East Slavonic Languages. Columbus: Slavica Publishers.

Diller, Anthony V.N. 1996. Thai orthography and the history of marking tone. Oriens Extremus 39(2): 228-254.

Dresher, B. Elan. 1994. The prosodic basis of the Tiberian Hebrew system of accents. Language 70:1-52.

Eisenberg, Peter. 1994. German. The Germanic languages, ed. by Ekkehard König and Johan van der Auwera, 349387. London and New York: Routledge.

Enfield, N.J. \& Diffloth, Gérard. 2009. Phonology and sketch grammar of Kri, a Vietic language of Laos. Cahiers de Linguistique - Asie Orientale 38(1): 3-69.

Glass, Andrew. 2000. A Preliminary Study of Kharoșțī Manuscript Paleography. MA thesis, Seattle: University of Washington.

Gregerson, Kenneth. 1969. A study of Middle Vietnamese phonology. Bulletin de la Société des Études Indochinoises, Nouvelle Série, XLIV: 2.

Griffiths, Arlo, Miyake, Marc, and Wheatley, Julian K. 2017a. Corpus of Pyu inscriptions. (http://hisoma.huma-num. fr/exist/apps/pyu/index2.html) (Accessed 7 November 2017).

Griffiths, Arlo, Hudson, Bob, Miyake, Marc, and Wheatley, Julian K. 2017b. Studies in Pyu epigraphy, I: state of the field, edition and analysis of the Kan Wet Khaung mound inscription, and inventory of the corpus. Bulletin de l'École française d'Extrême-Orient 103: 43-205.

Haudricourt, André-Georges. 1954a. Comment reconstruire le chinois archaïque. Word 10: $35^{-1} 364$.

Haudricourt, André-Georges. 1954b. De l'origine des tons en vietnamien. Journal asiatique 242: 68-82.

Haudricourt, André-Georges. 1972. Problèmes de Phonologie Diachronique. Paris: Société pour l'études langues africaines.

Haudricourt, André-Georges. 1975. Le système des tons du karen commun. Bulletin de la Société de Linguistique de Paris 70.1:339-43.

Holmes, Philip, and Ian Hinchliffe. 1997. Swedish: An Essential Grammar. London and New York: Routledge.

Jacques, Guillaume. 2004. Phonologie et Morphologie du Japhug (Rgyalrong). PhD dissertation, Paris: Université Paris VII - Denis Diderot. 
Jacques, Guillaume. 2014. Esquisse de Phonologie et de Morphologie Historique du Tangoute. Leiden: Global Oriental. Jacques, Guillaume. 2016. Tonogenesis and tonal alternations in Khaling. Tone and Inflection, ed. by Enrique L. Palancar and Jean Léo Léonard, 41-66. Berlin, New York: Mouton de Gruyter.

Jacques, Guillaume. 2018. A grammar of Japhug (the noun phrase). https://www.academia.edu/36275442/A_grammar_of_Japhug_the_noun_phrase. Accessed 6 February 2019.

Jones, Robert B. 1961. Karen Linguistic Studies: Description, Comparison, and Texts. University of California Publications in Linguistics, Vol. 25. Berkeley and Los Angeles: University of California Press, 1961.

Katō Atsuhiko. 加藤昌彦. 2005. ピュー語とカレン系諸言語の類似性. http://user.keio.ac.jp/ kato/Pyu_Karen. pdf. Accessed 4 June 2015.

Katō Atsuhiko. 加藤昌彦. 2018. How did Haudricourt reconstruct Proto-Karen tones? Reports of the Keio Institute of Cultural and Linguistic Studies 49: 21-44.

Krech, Uwe. 2012. A preliminary reassessment of the Pyu Faces of the Myazedi inscriptions at Pagan. Medieval Tibeto-Burman Languages, ed. by Nathan W. Hill, 121-169. Brill's Tibetan Studies Library,13. Leiden: Brill.

Li Yaming. 李亞明. (ed.) 2003. 《漢英上海口語詞典》。上海: 上海交通大學出版社。

Hanbo Liao. 2016. Tonal development of Tai languages. MA thesis, Chiang Mai: Payap University.

Luangthongkum, Theraphan. 2013. A view on Proto-Karen phonology and lexicon. Unpublished ms. contributed to STEDT. http://stedt.berkeley.edu/ stedt-cgi/rootcanal.pl/source/TL-PK. Accessed 17 October 2017.

G.H. Luce, 1985. Phases of Pre-Pagán Burma: Languages and History. 2 vols. Oxford: Oxford University Press.

G.H. Luce n.d.a A. Luce Collection, MS 6547, box 7, folder 2, page 015, National Library of Australia. http: //sealang. net/resolve/test/getdjvu.pl?text=luce\&page=ms6574-7-2: 012a-015. Accessed 25 June 2016.

G.H. Luce n.d.b B. Tircul tones. Luce Collection, MS 6574-7, oo6a. National Library of Australia. http://sealang.net/ resolve/test/getdjuu.pl?text=luce\&page=ms6574-7-4: 0o6a. Accessed 7 November 2015 .

Manson, Ken. 2009. Prolegomena to reconstructing Proto-Karen. La Trobe Working Papers in Linguistics 12.

Martin, Samuel E. 1992. A Reference Grammar of Korean. Rutland and Tokyo: Charles E. Tuttle Company.

Masica, Colin P. 1991. The Indo-Aryan Languages. Cambridge: Cambridge University Press.

Miles, James. 2016. Documentation of a Pyu inscription (PYU167). Data set.. http: //doi.org/10.5281/zenodo.823753. Accessed 25 July 2019.

Miyake, Marc Hideo. 2003. Old Japanese: A Phonetic Reconstruction. London and New York: Routledge.

Miyake, Marc Hideo. 2012. Complexity from compression: a sketch of pre-Tangut. Тангуты в центральной Азии: сборник статей в честь 8о-летия проф. Е. И. Кычанова, ed. by Irina Popova. 244-261. Moscow: Oriental Literature.

Miyake, Marc Hideo. 2017. A sketch of Pyu synchronic phonology. Presentation at the $27^{\text {th }}$ Annual Meeting of the Southeast Asian Linguistics Society, Padang, Indonesia.

Miyake, Marc Hideo. 2018. Pyu unique non-Indic akșaras (version 181222). Data set. http://doi.org/10.5281/ zenodo.252585. Accessed 25 December 2018.

Nishi Yoshio. 西義郎. 1999. Four papers on Burmese: Toward the History of Burmese (the Myanmar language). Tokyo: Institute for the Study of Languages and Cultures of Asia and Africa, Tokyo University of Foreign Studies.

Norquest, Peter. 2016. A Phonological Reconstruction of Proto-Hlai. Leiden: Brill.

Pinnow, Heinz-Jürgen. 1979. Reflections on the history of the Khmer phonemic system. Mon-Khmer Studies 8: 103-130.

Pulleyblank, Edwin G. 1991. Lexicon of Reconstructed Pronunciation in Early Middle Chinese, Late Middle Chinese, and Early Mandarin. Vancouver: University of British Columbia Press.

Ratliff, Martha. 2010. Hmong-Mien Language History. Canberra: Pacific Linguistics, School of Culture, History and Language, College of Asia and the Pacific in association with the Centre for Research in Language Change, The Australian National University. 
Rothstein, Robert A. 1993. Polish. The Slavonic Languages, ed. by Bernard Comrie and Greville G. Corbett, 686-758. London and New York: Routledge.

Sawalha, M.S. C. Brierley, and E. Atwell. 2012. Prosody prediction for Arabic via the open-source boundaryannotated Qur'an corpus. Journal of Speech Sciences 2(2): 175-191.

Shafer, Robert. 1943. Further analysis of the Pyu inscriptions. Harvard Journal of Asiatic Studies 7(4): 313-366.

Shevelov, George Y. 1993. Ukrainian. The Slavonic Languages, ed. by Bernard Comrie and Greville G. Corbett, 947988. London and New York: Routledge.

Shorto, Harry L. 1971. A Dictionary of the Mon Inscriptions from the Sixth to the Sixteenth Centuries: Incorporating Materials Collected by the Late C.O. Blagden. Oxford: Oxford University Press.

Simons, Gary F. and Charles D. Fennig (eds.). 2018. Ethnologue: Languages of the World, Twenty-First Edition. Dallas, Texas: SIL International. http://www.ethnologue.com. Accessed 6 February 2019.

Sohn, Ho-min, and B.W. Bender. 1973. A Ulithian Grammar. Canberra: Department of Linguistics, Research School of Pacific Studies, The Australian National University.

Stone, David. 1993. Slovak. The Slavonic Languages, ed. by Bernard Comrie and Greville G. Corbett, 533-592. London and New York: Routledge.

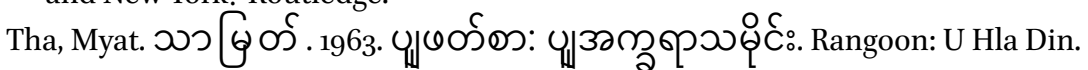

Turner, R.L. 1962-1966. A Comparative Dictionary of Indo-Aryan Languages. London: Oxford University Press.

Wei, James, and Jerold A. Edmondson. 2008. Sui. The Tai-Kadai Languages, ed. by Anthony V.N. Diller, Jerold A. Edmondson, and Luo Yongxian, 585-595. London and New York: Routledge.

Whitney, William Dwight. 1896. A Sanskrit Grammar, Including Both the Classical Language, and the Older Dialects, of Veda and Brahmana. 3rd ed. Leipzig: Breikopf and Härtel, Boston: Ginn \& Company.

Van Driem, George. 1993. A Grammar of Dumi. Berlin: Mouton de Gruyter.

Yabu Shirō. 數司郎. 1996. 字音質. 言語學大辭典第6卷術語編, ed. by 亀井孝 Kamei Takashi et al., 625-626. 東京: 三省堂.

Tongyin Yang and Jerold A. Edmondson. 2008. Kam. The Tai-Kadai Languages, ed. by Anthony V.N. Diller, Jerold A. Edmondson, and Luo Yongxian, 509-584. London and New York: Routledge.

Yanson, Rudolf. 2015. Predictability of phonological changes in Burmese. Archiv Orientální 83(1): 95-115. 


\title{
驃語音韻研究之二：韻母
}

\author{
Marc Miyake \\ 大英博物館 \\ amritavira@gmail.com
}

\section{摘要}

驃語是已消亡的一種語言, 公元第一千年以及其後數百年間, 曾使用於現今上緬甸地區。從基本詞彙判 断, 驃語應屬於漢藏語系。這種語言仍保存在以印度系統的文字書寫的碑文之上。本研究根據這些碑文的 拼音形式, 重建了驃語的韻母, 認為驃語有七個元音, 十八個尾輔音, 沒有聲調。前期學者曾將驃文的下 加音點解釋為聲調符號, 本文則認為它們代表的是擦音聲母。

\section{關鍵詞}

驃語、漢藏語系、音韻系統、古語構擬、韻母、聲調 